\title{
"Iura novit curia" y el Proyecto de Código PROCESAL Civil: ¿PARA QUÉ SIRVE DEFINIR LOS PODERES DEL JUEZ EN LA APLICACIÓN DEL DERECHO?
}

["Iura novit curia" and the Project of the Code of Civil Procedure: What the Faculties of the Judge are for in Applying the Law?]

\author{
IVÁn Hunter Ampuero* \\ Universidad Austral de Chile
}

\begin{abstract}
RESUMEN
El presente trabajo tiene por finalidad definir el alcance del poder del juez para aplicar el Derecho en ciertas instituciones jurídico-procesales en el marco de la reforma al Proceso Civil. Para ello se ha tomado una posición determinada fundada en ciertas concepciones del proceso civil y la jurisdicción como mecanismo tutelado de derechos, para luego relacionarlas con el rol del abogado en el proceso civil y la contradicción. En ese contexto se enfrenta el problema respecto del
\end{abstract}

\begin{abstract}
This work is aimed at determining the scope of the judge's powers in applying the Law to certain procedural-legal institutions within the framework of the Civil Procedure reform. To this end, a specific position, based on certain notions of the civil procedure and of the jurisdiction as a rights protection mechanism, has been taken and then related to the role of the lawyer in the civil procedure and in contradiction. Within this context, the problem on the concurrent actions
\end{abstract}

RECIBIDO el 30 de abril y ACEPTADo el 10 de junio de 2013

* Doctor en Derecho por la Universidad Carlos III de Madrid y magíster en Derecho por la Universidad Austral de Chile. Profesor de Derecho Procesal de la Universidad Austral de Chile. Dirección postal: Facultad de Ciencias Jurídicas, Universidad Austral de Chile, Campus Isla Teja, Valdivia, Chile. Correo electrónico: ivanhunter@ uach.cl Este trabajo fue realizado en el marco y con el financiamiento del Proyecto Fondecyt Iniciación $\mathrm{N}^{\circ} 11110185$, titulado "Iura novit curia". La aplicación judicial del Derecho en el Proyecto de Código Procesal Civil”, del cual el autor de este trabajo es su investigador responsable. 
concurso de acciones y normas jurídicas, la modificación de la demanda y la cosa juzgada, precisando hasta dónde alcanza la vinculación del juez a los fundamentos jurídicos de la demanda.

Palabras Clave

Contradicción - Aplicación judicial del derecho - Iura Novit Curia - Principio dispositivo. and legal norms, the modification of the complaint and the res judicata is faced, determining the scope of the relationship of the judge with the legal grounds of the complaint.

\section{KEYWORDS}

Contradiction - Legal application of the law - Iura Novit Curia - Principle under which the parties delimit the scope of proceedings.

\section{INTRODUCCIÓN}

Hace algún tiempo que la investigación en el Derecho procesal civil se ha ido situando preferentemente en el vasto campo de la prueba judicial. Este enfoque, por cierto absolutamente necesario, ha perdido de vista que toda la actividad probatoria que se despliega en el proceso judicial se destina a lograr la aplicación de las normas jurídicas invocadas por el actor como sustento de su demanda. La determinación del objeto de la prueba queda definida por la fijación de las normas jurídicas que resultan potencialmente aplicables a la controversia. Serán los presupuestos de hecho de las normas jurídicas el centro de la actividad probatoria. Por eso la selección adecuada de las normas aplicables es tan relevante para el éxito de la pretensión del actor y la satisfacción de los derechos e intereses que el ordenamiento tutela. Sin embargo, esto no parece tan asumido.

En el Derecho nacional prácticamente no se ha investigado con una mirada científica el alcance de los poderes de los jueces para aplicar el Derecho. Si los jueces cuentan con algún margen de libertad para separarse de los fundamentos jurídicos expuestos por el actor para conceder una pretensión en base a argumentos diferentes sigue siendo resorte del intérprete de turno. Mientras que algunos, como nuestra jurisprudencia, entienden que ese poder es prácticamente absoluto ${ }^{1}$, otros en cambio, con más prudencia establecen límites derivados de la contradicción o el principio dispositivo ${ }^{2}$. Evidentemente en nuestra práctica judicial sigue primando aquella tajante separación entre cuestiones de hecho y de derecho, tan afianzada y aprendida a propó-

\footnotetext{
${ }^{1}$ Véase: Hunter, Iván, "Iura novit curia" en la jurisprudencia civil, en Revista de Derecho de la Universidad Austral de Chile, 2 (2010), pp. 201-216.

${ }^{2}$ Ormazabal, Guillermo, "Iura novit curia". La vinculación del juez a la calificación jurídica de la demanda (Madrid, Marcial Pons, 2007), p. 119.
} 
sito del recurso de casación en el fondo. Pero el problema de si el juez tiene el control total de los materiales jurídicos, o por el contrario, está sometido a los extremos jurídicos en que las partes han situado la controversia, tiene repercusiones mucho más acabadas de lo que podría esperarse.

El presente trabajo pretende abordar con una mirada crítica algunos aspectos problemáticos y jurídicamente relevantes de la aplicación judicial del Derecho en el ordenamiento nacional. Si bien es cierto que la práctica judicial ha articulado una versión activa del juez en el ámbito de la aplicación de las normas jurídicas, llevarlo a los casos específicos genera algunas dificultades. Y los problemas derivan, esencialmente, cuando se trata de conjugar esa libertad del juez con algunas instituciones o reglas del proceso civil que están destinadas a ser aplicadas en el marco de la reforma al proceso civil, y muy especialmente en el Proyecto de Código Procesal Civil (en adelante PCPC.). Para esa finalidad he seleccionado cuatro instituciones: el concurso de normas, el concurso de acciones, la modificación de la demanda y la cosa juzgada.

Esta selección no es arbitraria ni aleatoria. Al contrario, grafican los problemas más frecuentes en la práctica judicial al momento de aplicar las normas jurídicas al caso concreto, y están vinculadas con la formación del objeto del proceso. En otras palabras tanto jueces como operadores suelen preguntarse sobre el alcance de los poderes del juez en el ámbito de la aplicación de las normas jurídicas cuando se enfrentan a ciertas instituciones precisas. De igual manera, he huido de la forma en que tradicionalmente suelen abordarse estas problemáticas, puesto que lejos de clarificar la solución, la complica en igual proporción a cuantas teorías del objeto del proceso existan. De igual forma, pretendo reflexionar acerca de cómo las cuestiones procedimentales suelen influir en la posibilidad de que los jueces apliquen libremente el derecho. Este iter supone, como es lógico, referirse a una serie de cuestiones generales que justifiquen la postura que se adopte para cada institución en particular.

Desde este perspectiva he querido (II) hacerme cargo de la relación entre fundamento de la demanda y fundamentación jurídica, y su vinculación con el principio dispositivo. Luego (III) cimentar tres ideas que influyen -o debieren influir- en el alcance del poder del juez para aplicar el Derecho. Por último (IV) y como reflejo de estas ideas preliminares, he querido precisar para cada institución específica cómo se relaciona la posibilidad del juez de aplicar los materiales normativos. He finalizado con las conclusiones $(\mathrm{V})$. 


\section{EL PRINCIPIO Dispositivo:}

\section{FUNDAMENTO Y FUNDAMENTACIÓN JURÍDICA DE LA DEMANDA}

Los problemas que abordaré en este trabajo tienen una importancia esencialmente práctica, que se derivan de la ausencia en los cuerpos legislativos de reglas claras y sencillas que los resuelvan. Si el juez es o no libre para la aplicación del Derecho parece ser un problema que no solo se produce al momento de dictar sentencia sino que está presente en una serie de institutos procesales y a lo largo de todo el iter procedimental. En la medida que la aplicación de las normas invocadas está supeditada a la prueba de sus presupuestos de hecho la correcta definición de los parámetros jurídicos será vital para la identificación del objeto probatorio.

No obstante, parece adecuado resolver preliminarmente un tema de apariencia terminológica pero que tiene importantes repercusiones conceptuales, y que hasta el momento no ha sido abordado con claridad. Es frecuente en la doctrina, como también en la jurisprudencia, escuchar acerca de la libertad de los jueces para aplicar el Derecho en el caso concreto. Así se habla casi indistintamente de "calificar jurídicamente la demanda", como también de "fundamento jurídico", "fundamentación jurídica", o de aplicar los "materiales normativos", "normas jurídicas" y "estatuto jurídico” a la pretensión ${ }^{3}$. Otros, para representar el mismo fenómeno echan mano al viejo aforismo "iura novit curia" ${ }^{4}$. Se trata de expresiones que suelen utilizarse como sinónimas, pero que en algunos institutos procesales específicos -como en los que se pretenden investigar- tienen un significado especial.

$\mathrm{Al}$ respecto me parece oportuno dejar establecida la distinción entre fundamento jurídico y fundamentación jurídica ${ }^{5}$, especialmente en su vinculación con el principio dispositivo que orienta la distribución de tareas en el

${ }^{3}$ En este grupo, el antiguo pero pionero trabajo de PrIETo, Leonardo, El cambio del punto de vista jurídico, en Revista de Derecho Procesal, 1 (1956), p. 3; PAdura, Teresa, Fundamentación de la sentencia, preclusión y cosa juzgada. Su régimen en la LEC 1/2000 (Valencia, Tirant Lo Blanch, 2002), pp. 80-81; y SEnTís, Santiago, El juez y el Derecho (Buenos Aires, Ediciones Jurídicas Europa-América, 1957), pp. 9 ss.

${ }^{4} \mathrm{GUASCH}$, Sergio, El hecho y el Derecho en la casación civil (Barcelona, J. M., Bosch, 1998), p. 167; Tapia, Isabel, El objeto del proceso. Alegaciones. Sentencia. Cosa juzgada (Madrid, La Ley, 2000), p. 71; YllesCa, Rafael, El principio “iura novit curia” y la posición del abogado en el proceso, en La Ley, 3 (1994), pp. 826; y EzQUiaGA, Francisco, "Iura novit curia" y aplicación judicial del Derecho (Valladolid, Lex Nova, 2008), p. 18.

${ }^{5}$ Tempranamente la doctrina fue precisando con plena claridad la diferencia entre los motivos que afectan a la fundamentación jurídica de la pretensión, de aquellos que conforman la causa de pedir. Véase: CORTÉs, Valentín, Las facultades del tribunal ex art. 43,2 de la LJCA. Nota a la sentencia de la Sala cuarta del Tribunal Supremo de 17 de octubre de 1980, en Revista Justicia, 81 (1981), p. 242. 
proceso civil. Por fundamento jurídico debemos entender la adscripción que un litigante formula de unos hechos a unas determinadas normas jurídicas que le permite obtener el efecto jurídico pretendido en la demanda. Este ejercicio requiere que el demandante seleccione unos hechos que justifican la petición concreta en contra del demandado. De esto se sigue la estrecha vinculación entre hechos, normas jurídicas y efecto pretendido. Cuando esta relación es perfecta no se produce inconveniente alguno con la aplicación que pueda hacer el juez del Derecho. Sin embargo, pueden haber situaciones en que el actor plantea en la demanda una multiplicidad de hechos, los que permiten lograr el efecto pretendido pero bajo estatutos jurídicos diversos e incompatibles entre sí. En este caso, el fundamento jurídico quedará delimitado por aquellos datos fácticos -solo aquellos- que según el actor permiten conceder el efecto jurídico. Son los materiales jurídicos invocados los que determinan los hechos relevantes. El juez no podría, en principio, considerar otros hechos distintos como presupuesto de las normas aplicables ${ }^{6}$.

De esta forma la alegación en sentido técnico correspondería a lo que la doctrina entiende como alegaciones identificadoras de la causa de acción, que quedan sustraídas del ámbito del principio "iura novit curia", en oposición a las alegaciones simplemente normativas que pueden ser suplidas por el juez en tanto suponen la aplicación de normas jurídicas. La mayoría de la doctrina, especialmente la italiana, entiende que en la actividad alegatoria de la parte, esto es, en el ejercicio de adscribir unos hechos a los propuestos fácticos de determinadas normas jurídicas, hay una manifestación del principio dispositivo. En la medida que a las partes les corresponde introducir el material fáctico en la demanda también determinan inmediatamente cuál será el estatuto jurídico aplicable a la controversia. Se trata, por tanto, de un espacio reservado exclusivamente al ejercicio de la autonomía privada, en la que el juez nada puede hacer sin vulnerar el principio dispositivo. Las partes al momento de alegar unos hechos disponen además de su relevancia jurídica. Por eso, siguiendo a Buoncristiani, es posible entender que la alegación de un hecho consiste en la atribución de un valor jurídico a un acontecimiento para

${ }^{6}$ Señalar que el juez no puede modificar los hechos alegados por las partes es apenas una consecuencia natural y obvia del principio dispositivo y de la imparcialidad que debe observar en el proceso. Pero en esta materia lo relevante es que el juez no modifique el ámbito de relevancia con que un litigante ha introducido un determinado dato o acontecimiento fáctico. Por eso, es correcto lo explica YlLeSCA, R., cit. (n. 4), p. 829, en el sentido que resulta prácticamente imposible o al menos muy difícil entender que la sustitución de una norma jurídica en un proceso no conlleve la modificación de los hechos. En cierta forma puede suceder que los hechos se mantengan intangibles en cuanto a su materialidad, pero con cambios sustanciales en su relevancia jurídica.

${ }^{7}$ Véase: CorTÉs, V., cit. (n. 5), p. 242. 
producir un efecto jurídico determinado ${ }^{8}$. En este extremo de la pretensión, los litigantes serían los únicos habilitados para disponer que un hecho, en principio irrelevante, pueda situarse en la base de la pretensión.

Por otra parte, fundamentación jurídica consistiría en la invocación de las razones jurídicas que permiten justificar o sustentar esa adscripción de hechos a las normas jurídicas concretas ${ }^{9}$. Consiste en un proceso de argumentación, que se sustenta tanto en hechos, por lo general secundarios, como en la utilización de las herramientas jurídicas vinculadas a la interpretación. La fundamentación jurídica tiene más bien una función dialéctica y persuasiva, en la medida que supone exponer las razones para apoyar una decisión eventualmente favorable del juez, y que el efecto jurídico pretendido se desprende de los hechos y normas invocadas. En otras palabras, la fundamentación jurídica representa aquella indispensable justificación que requiere toda demanda o pretensión para ser acogida ${ }^{10}$. No se trata, como explica Nieva, de la simple cita de un artículo o norma legal, sino del razonamiento jurídico expresado en la demanda o en la sentencia ${ }^{11}$.

De esta manera, al menos para efectos de esta investigación, cuando se haga referencia al poder del juez para aplicar el Derecho hacemos alusión a lo que aquí hemos descrito como fundamento jurídico. La posibilidad de que el juez se aparte de los materiales normativos, estatuto jurídico, etc., que sustentan una determinada pretensión está relacionada con la adscripción de los hechos a unas normas que permiten obtener el efecto deseado. Por eso la libertad de los jueces para justificar jurídicamente una pretensión no forma

${ }^{8}$ Buoncristiani, Dino, L'allegazione dei fatti nel processo civile. Profili sistematici (Torino, Giappichelli Editore, 2001), p. 26. En esta categoría se encontrarían todos los denominados hechos principales. Véase, entre otros: Cappellettri, Mauro, El testimonio de la parte en el sistema de la oralidad. Contribución a la teoria de la utilización probatoria del saber privado de las partes en el proceso civil (La Plata, Librería Editorial Platense, 2002), pp. 319-320; y CAVAllone, Il giudice e la prova nel processo civile (Padova, Cedam, 1991), p. 99.

${ }^{9}$ Véase, al respecto: Comanducci, Paolo, Alcuni problema concettuali relativi alla applicazione del diritto, en Diritto e Questioni Pubbliche, 1 (2011), pp. 121-122.

${ }^{10}$ ITURRALDe, Victoria, Justificación judicial: Validez material y razones, en Analisi e Diritto, 9 (2004), p. 119. La jurisprudencia, para el contexto de la motivación de la sentencia, ha comprendido a cabalidad esta distinción al señalar que "surge toda la distinción racional sobre lo que efectivamente constituye el fundamento del fallo por parte de los jueces, distinguiendo lo que son las motivaciones, fundamentaciones, justificaciones y argumentaciones, resolviéndose por la jurisprudencia comparada que hay ausencia de fundamento tanto cuando éste se encuentra ausente, como cuando la ausencia es parcial o son insuficientes los expresados, al igual que al existir incoherencia interna, arbitrariedad e irrazonabilidad" (Corte Suprema, sentencia de 2 de noviembre de 2011, rol 6065-22010).

${ }^{11}$ Nieva, Jordi, La cosa juzgada (Barcelona, Atelier, 2006), p. 182. 
parte del problema en cuestión, y se relaciona más bien a materias relativas a la motivación de la sentencia.

III. EL ROL DEL JUEZ EN LA APLICACIÓN DEL DERECHO Y LA TUTELA EFECTIVA DE LOS DERECHOS DE LOS JUSTICIABLES

Las técnicas son formas de dar respuesta a finalidades eminentemente políticas. Una regla jurídica procesal por más neutra que parezca esta sumida en un engranaje de concepciones ideológicas, y que muestran el interés del legislador de acercarse a una determinada visión del proceso civil. Por eso, la respuesta a las interrogantes específicas de cada instituto procesal, obedecen a ciertas ideas previas acerca del rol del juez y los abogados en el proceso civil, y la función de la jurisdicción en la tutela de los derechos de los ciudadanos ${ }^{12}$. Estas ideas me gustaría explicitarlas, como paso previo a la respuesta concreta. Para ello quiero referirme, en primer lugar, a la idea de legitimación de la decisión judicial como valor determinante en la aplicación de las normas jurídica; en segundo lugar, dar cuenta del rol preponderante de la contradicción en la obtención de la regla jurídica aplicable. Y por último, quiero referirme al rol que juegan quienes participan de la controversia: partes y juez.

\section{La legitimación del poder jurisdiccional a través de la tutela efectiva de} los derechos de los ciudadanos.

La tutela efectiva de un derecho -en la medida que se pruebe su existencia y vulneración-, no puede ser descargada exclusivamente en los litigantes, en la medida que otorgar protección de un derecho e interés es una finalidad que asume el Estado como garantía para los ciudadanos ${ }^{13}$. Esto significa que el juez deberá cumplir un rol relevante en la calificación jurídica de la pretensión, así como también en suplir o complementar los argumentos jurídicos

${ }^{12}$ De cómo el derecho a la tutela jurisdiccional efectiva de los derechos de los ciudadanos condiciona la estructuración del proceso y la jurisdicción, puede verse: MARINONI, Luiz - PÉRez Ragone, Álvaro - NúÑez, Raúl., Fundamentos del proceso civil. Hacia una teoría de la adjudicación (Santiago, Legalpublishing, 2010), pp. 114-115.

${ }^{13}$ Para el Derecho comparado pueden verse: TAruffo, Michele, Páginas sobre la justicia civil (Madrid, Marcial Pons, 2009), p. 22; Comoglio, Luigi, I modeli di garanzia costituzionale del processo, en Rivista Trimestrale di Diritto e Procedura Civile, 3 (1991), p. 675; Ferrajoli, Luigi, "Principia iuris". Teoría del Derecho y de la democracia (Madrid, Trotta, 2007), pp. 637 ss.; y Pivetti, Marco, Per un processo civile giusto e ragionavole, en Civinin, Maria Giuliana - Verardi, Carlo Maria (coordinadores), Il nuovo articolo della Costituzione e il giusto proceso civile. Atti del Convegno dell Elba (Milano, FrancoAngeli Editore, 2001), p. 62. Para el derecho nacional: HunTER, Iván, La aplicación judicial del Derecho en el Proyecto de Código Procesal Civil, en Revista de Derecho de la Universidad Austral de Chile, 1 (2012), p. 200. 
esgrimidos por las partes. Si la obtención de la tutela de un derecho subjetivo e interés depende, en gran parte, de los materiales jurídicos que se empleen para derivar la petición concreta, resulta sensato que el Estado asuma un papel importante cuando las partes han fracasado en esa tarea ${ }^{14}$.

La participación del juez en la integración del material jurídico aplicable a un conflicto de intereses resulta importante. Es difícil concebir el correcto ejercicio jurisdiccional sin la posibilidad de que los jueces puedan suplir, corregir y modificar la invocación del Derecho contenido en la solicitud de tutela. Pero es aun más escabroso entender que la tutela solicitada por el ciudadano debe destinarse al fracaso en aquellas situaciones en que, justificando la titularidad del derecho y la plausibilidad fáctica de una pretensión, se yerra en el estatuto jurídico que se estima aplicable ${ }^{15}$. Como explica parte de la doctrina es bien difícil explicar a un ciudadano que puede ser justo un proceso que no sea capaz o al menos no esté orientado a hacer justicia ${ }^{16}$. Por este motivo entiendo que la verdadera protección de un derecho debe lograrse con total prescindencia de la habilidad del ciudadano para apuntar con la legislación correcta, ejercicio éste que puede resultar extremadamente complejo y hasta tortuoso. La pura acreditación de la titularidad de una posición subjetiva y su lesión por el demandado, deberían ser suficientes para que la jurisdicción pueda actuar aplicando las normas correctas y disponiendo los efectos que ella establece, siempre que haya sido solicitado por el ciudadano.

Pero a la razón ya expuesta, puede añadirse otra que no ha sido planteada directamente, al menos de la forma en que aquí quiere hacerse. Me refiero a la posibilidad de justificar el poder del juez para aplicar la norma correcta en la idea de legitimación de la actividad jurisdiccional, esto es, que las decisiones de nuestros tribunales son legítimas sí y solo sí son capaces de acertar con la tutela de un derecho o interés que el ordenamiento ha reconocido al ciudadano. No me parece muy aventurado aseverar que la legitimación social

${ }^{14}$ Hunter, I., cit. (n. 13), p. 201.

${ }^{15}$ Particularmente relevante, por la relación que hace entre aplicación judicial del Derecho y tutela judicial efectiva es la sentencia de la Corte de Apelaciones de Valdivia, rol No 897-2012, que en su considerando sexto expresó: "Que, en cuanto a la infracción del principio de pasividad alegada por la parte demandada, del análisis atento del libelo de oposición entablado en estos antecedentes, aparece que ello en ningún caso acontece, desde que el juez se encuentra facultado por ley para calificar juridicamente los hechos sometidos a su decisión, siendo absolutamente procedente en dicho ejercicio privativo y exclusivo, subsumir los hechos alegados en las causales establecidas por el legislador, máxime si en la instancia administrativa no se requiere contar con asesoría letrada para formular la oposición, lo que resulta del todo acorde con el debido proceso legal, y en especial con el derecho a una tutela juridica efectiva, consagrados en el artículo $19 \mathrm{~N}^{\circ} 3$ de la Constitución Politica".

${ }^{16}$ Pivetti, M., cit. (n. 13), p. 62. 
y política de la actividad que desarrollan los tribunales de justicia está ligada a la aceptación de sus decisiones. Como lo explica muy bien la doctrina "la legitimación democrática de quienes ejercitan la potestad jurisdiccional se ha querido encontrar, no ya en la fuente que posibilita su acceso al cargo (como acontece en los demás poderes públicos), sino en las exigencias que la sociedad demanda de sus jueces, en la calidad de la respuesta que la ciudadanía espera de ellos cuando se les somete el enjuiciamiento de un determinado conflicto" ${ }^{17}$. En otras palabras, la jurisdicción no goza de una legitimación de origen, pero sí puede legitimarse en su ejercicio ${ }^{18}$.

Podría pensarse que la función jurisdiccional se satisface con la aplicación adecuada de una norma jurídica a un caso concreto, pero esto no es necesariamente así. Cuando el juez aplica el ordenamiento para sustentar el rechazo de la demanda indicando que los materiales jurídicos no han sido correctamente invocados, esa decisión está ajustada al ordenamiento. Sin embargo, esa decisión puede dejar de tutelar un derecho e interés que otra norma del ordenamiento considera relevante, por eso que los jueces deben tener como misión proporcionar decisiones materialmente justas, determinando el verdadero interés prevaleciente en una disputa.

Por lo indicado, la jurisdicción debería aparecer dotada de las herramientas necesarias para evitar que una pretensión jurídicamente mal fundada pueda destinarse al fracaso, por el solo hecho de haber errado en la determinación del Derecho aplicable a la controversia. En eso debería consistir, precisamente, la esencia de la jurisdicción. En la medida que los jueces y tribunales resuelven los casos sometidos a su decisión propendiendo a la tutela de los derechos e intereses de los sujetos que justifican ser sus titulares, es posible afirmar que sus decisiones son legítimas. A mi juicio, gran parte de la auctoritas judicial, y por ende, la confianza que puedan depositar los ciudadanos en la institución jurisdiccional ${ }^{19}$, depende de esa posibilidad ${ }^{20}$.

${ }^{17}$ GARberí, José, Constitución y Derecho procesal. Los fundamentos constitucionales del Derecho procesal (Madrid, Civitas, 2009), p. 50.

${ }^{18}$ Véase, López, Luis, El Poder Judicial en el Estado Constitucional (Lima, Palestra Editores, 2001), p. 23.

${ }^{19}$ Explica Toharía, José, ¿Qué esperan los ciudadanos de la justicia? en Poder judicial y servicio público (Madrid, Consejo General del Poder Judicial, 2006), pp. 35 ss., en especial, p. 39, que los ciudadanos esperan que la justicia no sea nada más que una "buena justicia", cuestión que se logra, en gran forma, con eficiencia técnica y confiabilidad moral. Esta última se remite al plano de la legitimación social, esto es, el conjunto de cualidades observables del quehacer jurisdiccional que hacen que la ciudadanía reconozca confianza en el accionar jurisdiccional.

${ }^{20}$ Una decisión jurisdiccional que satisfaga de modo íntegro la necesidad de tutelar efectivamente los derechos de los ciudadanos no cumpliría su función si se limita a definir que el derecho invocado por el actor no es correcto. Una sentencia de esta na- 
Una decisión que se limite a observar que el estatuto jurídico invocado por el titular de un derecho o interés ha sido erróneamente alegado no sería necesariamente justa, puesto que dejaría de brindar protección a quien efectivamente la merece. Si bien esta sentencia se ajusta al ordenamiento al hacer aplicación de la ley, no debería de gozar de una legitimidad política ni constitucional, en la medida que no otorga protección a una relación jurídica existente y lesionada, por la sola razón de que el actor no fue lo suficientemente hábil para acertar en el Derecho aplicable. Esto supone cambiar el centro que tradicionalmente ha impregnado a la justicia (los operadores, técnicos o profesionales del derecho) para situarlo en el usuario, el ciudadano, en el sujeto que concurre al tribunal para obtener protección de un derecho que entiende es titular ${ }^{21}$.

Así concebida la legitimidad de la decisión judicial es un perfecto correlato de la confianza, protagonismo y robustecimiento que ha tenido el Poder Judicial en el Estado moderno; en primer lugar, porque los tribunales han asumido en el Estado moderno la delicada e importante tarea de controlar la actuación de los poderes públicos, especialmente del Poder Ejecutivo y la administración pública. El control de los límites legales, de la adecuación de la acción de los particulares y el Estado a los parámetros legislativamente establecidos, corresponde finalmente a los órganos que ejercen la jurisdicción; en segundo lugar, porque constitucionalmente una de las piezas esenciales para la protección de los derechos y libertades básicas de los ciudadanos son los tribunales de justicia ${ }^{22}$. Son ellos los llamados constitucionalmente a la defensa de los derechos fundamentales, sea directamente a través de las acciones establecidas en la propia Constitución, o mediante el esfuerzo de interpretar los textos legales conforme a la misma.

Hoy en día la jurisdicción forma parte de las garantías claves para el ejercicio de los derechos e intereses de los ciudadanos, y constituye el canal estatalmente consagrado para la reafirmación de la legalidad en la actuación de los órganos y servicios públicos, como de los demás ciudadanos en sus relaciones intersubjetivas. Las decisiones jurisdiccionales cobran cada vez

turaleza cumple un estándar mínimo de legalidad al aplicar la ley al caso sometido a su decisión, pero puede generar graves injusticias. Por eso el verdadero y real problema se produce cuando el juez, para acoger una demanda, requiere salirse del marco jurídico propuesto por el demandante. En consecuencia, el rechazo de la demanda en base a fundamentos y fundamentación jurídica diferente a la resistida por el demandado no constituye en realidad un problema para la justicia de la decisión.

${ }^{21}$ Toharía, J., cit. (n. 18), pp. $41-42$.

${ }^{22}$ Sigo las razones expuestas por Delgado, Luis, Constitución, Poder Judicial y responsabilidad (Madrid, Centro de Estudios Políticos y Constitucionales, 2002), p. 46. 
mayor importancia en la vida cotidiana ${ }^{23}$ y en la construcción de la justicia de las instituciones estatales, de manera que resulta difícil considerar justa a una institución que niegue la protección de un interés o derecho al ciudadano.

Existe un gradual cambio en las expectativas sociales respecto de la justicia; ya no es posible concebirla como el puro ejercicio del poder estatal, fría, lejana y distante al ciudadano, destinada a la resolución de casos desde la abstracción de las normas legales. Al contrario, su actual posición le impone la necesidad de legitimarse socialmente mediante la protección, celosa y efectiva de los derechos y libertades públicas24. "Si la verdadera y última razón de ser de la justicia son los ciudadanos, no los profesionales que la integran, lo esperable es que organice en consecuencia su andadura diaria ${ }^{25}$. No es posible ignorar que, en definitiva, la correcta invocación de las normas aplicables no es una cuestión que dependa directamente del ciudadano; la relación del ciudadano con el proceso, y por ende, con la jurisdicción, es siempre mediada y guidada por un profesional del Derecho, encargado de discernir y justificar las normas jurídicas aplicables. Esa realidad no puede ser desconocida por el legislador, al menos en lo que dice relación a las consecuencias de la errónea e imperfecta alegación del Derecho.

En otro orden de ideas la relación entre la verdad como finalidad de la prueba $^{26}$, y la posibilidad de que los jueces apliquen libremente el orden jurídico es una conexión crucial para la tutela de los derechos de los ciudadanos. Nada logra el proceso civil orientando sus decisiones hacia la verdad de los enunciados de hecho si el juez carece de la posibilidad de aplicar el Derecho que estime correcto para la protección de los derechos de los ciudadanos. Sería un esfuerzo inútil justificar la decisión en una genuina reconstrucción de los hechos, y a la vez, en la incorrecta invocación de los materiales jurídicos. Por otro lado, hay una clara necesidad de hacer coherente los esfuerzos probatorios de los litigantes con la aplicación potencial de las normas jurídicas. La actividad probatoria debe estar dirigida a lograr la aplicación de las normas jurídicas que se estiman aplicables para resolver si el ciudadano que reclama un derecho es su titular; por eso, la necesidad de llegar a la verdad por medio

${ }^{23}$ Indica LópEz, L., cit. (n. 17), p. 23, que: "las características que definen y singularizan la actividad jurisdiccional la convierten, probablemente, en la expresión del poder público que en forma más directa y decisiva afecta la esfera individual [...] la decisión del juez, es, por un lado, y frente a la actividad parlamentaria, una aplicación inmediata del Derecho que recae sin intermediarios sobre el ciudadano afectando sus bienes, su libertad, y su honor (y, en algunos países, su propia vida); y, por otro, y en contraposición con la actividad administrativa, se trata de una decisión final".

${ }^{24}$ Ibíd., p. 42.

${ }^{25}$ Ibíd.

${ }^{26}$ Sobre esto se ha escrito mucho. Por eso, véase, por todos: FerRer, Jordi, La valoración racional de la prueba (Madrid, Marcial Pons, 2007), p. 30. 
de la prueba cobra todo sentido cuando el juez puede aplicar las normas correctas. Si el juez quedase atrapado a los supuestos de hecho de las normas alegadas por las partes, intentar alcanzar la verdad de las proposiciones fácticas únicamente cobraría sentido cuando el litigante ha sido capaz de acertar con las normas. Los hechos probados coinciden con los presupuestos de las normas jurídicas aplicables. Pero cuando el actor ha errado en la invocación de las normas jurídicas entonces la prueba irá encaminada a lograr la verdad de hechos que no calzan con los supuestos de esas normas, impidiendo, por tanto, la adjudicación de las consecuencias jurídicas queridas por el actor.

\section{La contradicción como clave en la tutela de los derechos de los ciudada-} nos.

Tradicionalmente el ámbito de aplicación del Derecho por parte de los jueces ha sido explicado a propósito de las discusiones que giran en torno a los elementos que conforman el objeto del proceso y en especial a la causa de pedir ${ }^{27}$. No obstante, su enfoque en el último tiempo ha estado ligado al respeto del derecho de defensa de los justiciables ${ }^{28}$. Este cambio de perspectiva resulta vital.

${ }^{27}$ Véase en la doctrina, y con un carácter no exhaustivo: Romero, Alejandro, La cosa juzgada en el proceso civil chileno. Doctrina y jurisprudencia (Santiago, Editorial Jurídica de Chile, 2002), p. 72; El mismo, Curso de Derecho procesal civil. La acción y la protección de los derechos. (Santiago, Editorial Jurídica de Chile, 2006), p. 21. Para el Derecho comparado: GARNICA, Juan, El principio “iura novit curia” y la determinación del objeto del proceso en el Proyecto de reforma de la Ley de Enjuiciamiento Civil, en La Ley, 1 (1999), p. 1713; Tapia, Isabel, cit. (n. 4), p. 23; Berzosa, Victoria, Demanda, "causa petendi" y objeto del proceso (Córdoba, Ediciones El Almendro, 1984), p. 46; Millán, Carlos, La incongruencia civil (Madrid, Tecnos, 1983), p. 55; De la Oliva, Andrés, Sobre la congruencia de la sentencia civil, en Revista Jurídica Española La Ley, 2 (1982), p. 897; y Normand, Jacques, I poteri del giudice e delle parti quanto al fondamento delle pretensa controverse, en Rivista di Diritto Processuale, 2 (1998), p. 724.

${ }^{28}$ Puede verse, en este sentido: HunTER, Iván, El principio dispositivo y los poderes del juez, en Revista de Derecho de la Pontificia Universidad Católica de Valparaíso, 35 (2010), p. 176; EzQuiaga, F., cit. (n. 4), p. 57; Gentili, Aurelio, Contraddittorio e giusta decisione nel proceso civile, en Rivista Trimestrale di Diritto e Procedura Civile, 2 (2009), p. 752; Ormazabal, G., cit. (n. 2), pp. 105 ss.; Trocker, Nicolò, Processo civile e costituzione. Problemi di Diritto tedesco e italiano (Milano, Giuffrè, 1974), pp. 645 y 682; Tarzia, Giuseppe, Poteri delle parti epoteri del giudice en Problemi del proceso civile di cognizione (Padova, Cedam, 1989), p. 318; FERri, Corrado, Sull'effettività del contraddittorio, en Rivista Trimestrale di Diritto e Procedura Civile, 42 (1989), p. 793; Chiarloni, Sergio, Questioni rilevabili d'ufficio, diritto di difesa e "formalismo delle garanzie", en Rivista Trimestrale di Diritto e Procedura Civile, 1 (1987), pp. 583 ss.; ANDOLInA, Italo - Vignera, Giuseppe, I fondamento costituzionali della giustizia civile. Il modello costituzionale del processo civile italiano (Torino, Giappicchelli, 1997), p. 174; Verde, Giovanni, Profili del proceso civile. Parte generale ( $2^{\circ}$ edición, Napoli, 
En primer lugar, porque las tesis clásicas no solo no permitían resolver el problema de fondo trasladándolo a otra perspectiva ${ }^{29}$, sino que además dejaban al ciudadano en una situación de completa desprotección en sus derechos. Si el juez constataba la existencia de un derecho lesionado, pero cuya protección podía lograr en base a un estatuto jurídico diferente, la contradicción operaba como límite a la decisión, impidiendo la tutela del derecho. Con este proceder se hacía efectivo el contradictorio desde que se limitaba al juez en la posibilidad de salirse del área del debate ${ }^{30}$.

Esta visión del contradictorio tiende a alcanzar una justicia procedimental; el juez no puede salirse de los términos del debate y resolver la controversia con total prescindencia a la discusión o argumentos planteados por las partes, pues infringe el derecho de defensa al sorprender a una de las partes con argumentos nuevos y ajenos al debate. El derecho del ciudadano de participar en contradicción en la formación del contenido material de la sentencia sería vulnerado al permitir que el juez justifique su decisión en elementos normativos ignorados por las partes. Una decisión denegatoria sería justa desde el punto de vista procedimental, al ajustarse a las garantías procesales de los justiciables. Esta tesis del contradictorio corresponde a la plasmación del principio de igualdad formal de las partes, y tiende a satisfacer la posibilidad de que los litigantes participen activamente en el desarrollo del proceso y de influir, con su propia actividad, en la formación de la decisión jurisdiccional ${ }^{31}$. Sin embargo, no es seguro que la justicia de la decisión dependa de la corrección del método ${ }^{32}$.

En el Estado moderno ya no es suficiente la legitimación de una decisión judicial por medio de su ajuste al proceso legalmente establecido, como tampoco por el respeto a las garantías procesales constitucionalmente consagradas. El cumplimiento de las garantías es tan solo un presupuesto necesario e indispensable para que el juez pueda dictar sentencia, pero no hacen que la decisión sea automáticamente justa; es necesario, además, que el contenido material de la decisión tenga la misma cualidad de justicia, esto es, que se base en una genuina reconstrucción de los hechos y en una correcta aplicación de

Jovene, 1988), p. 97; Comoglio, Luigi, Giurisdizione e proceso nel quadro delle garanzie costituzionali, en Rivista Trimestrale di Diritto e Procedura Civile, 4(1994), p. 1085; y CABRAL, Antonio, Il principio del contraddittorio como diritto d'influenza e dovere di dibattito en Rivista di Diritto Processuale, 2 (2005), pp. 450 ss.

${ }^{29}$ Hunter, I., cit. (n. 13), p. 206.

${ }^{30}$ Gentili, A., cit. (n. 27), p. 755.

${ }^{31}$ CAPONI, Remo, Brevi note sul contraddittorio in condizioni di parità nel processo civile, en Civinini, M. G. - VerARDi, C. M. (coordinadores), Il nuovo articolo della Costituzione e il giusto proceso civile. Atti del Convegno dell Elba (Milano, FrancoAngeli Editore, 2001), p. 282.

${ }^{32}$ Gentili, A., cit. (n. 27), p. 755. 
la norma jurídica. Sobre todo es justa aquella decisión que, respetando las garantías formales mínimas, permite conceder la tutela a quien efectivamente la merece, sin perjuicio de que el justiciable haya fracasado en su esfuerzo de invocar las normas aplicables. Solo de esta forma es posible afirmar que se tutelan los derechos de los ciudadanos y se legitima el poder jurisdiccional por el contenido sustancial de sus decisiones.

La contradicción, por lo tanto, sirve para corregir la insuficiencia de la justicia formal o procedimental como legitimadora del acto de autoridad que es la sentencia, permitiendo que el juez, o que incluso las partes, sometan a discusión los extremos jurídicos no alegados por el actor, y que constituyen los parámetros bajo los cuales la pretensión encuentra asidero jurídico. Con esto la contradicción deja de presentarse como un límite de la decisión para convertirse en la facilitadora de una decisión sustancialmente justa, permitiendo que el juez utilice con libertad sus poderes de aplicación normativa ${ }^{33}$. Se trata, como bien afirma un autor, que la justicia de la decisión aparezca como consecuencia del mérito del contradictorio ${ }^{34}$. De ahí que sea natural entender que la regulación acerca de la posibilidad del juez para aplicar el Derecho no sea otra que la regulación de cómo y cuándo debe efectuarse la contradicción en el proceso ${ }^{35}$.

\section{Juez y abogados en la búsqueda de la "regula iuris".}

Me gustaría dejar en claro algunas ideas relacionadas con la participación de las partes en la formulación de la regla jurídica que será aplicable a la relación jurídica controvertida. No es especialmente dificultoso comprender que los litigantes gozan del derecho a incidir sobre el procedimiento y éxito de la controversia. Esto constituye una emanación obligada del derecho de defensa y es consecuencia de la garantía fundamental del debido proceso. En términos reales, la contradicción se concreta en la posibilidad de formular alegaciones y presentar las pruebas necesarias y convenientes para la conducción a un resultado favorable de la pretensión ${ }^{36}$.

${ }^{33}$ Andolina, I. - Vignera, G., cit. (n. 27), p. 174; Ferri, C., cit. (n. 27), pp. 794.795. Puede verse con especial atención: Sommaggio, Paolo, La centralità del contraddittorio nell esperienza giuridica. Prima riflesioni per una teoria radicale, en Diritto \& Questioni Pubbliche, 7 (2007), pp. 100 ss. Esto es, en cierta medida, lo que Picardi entiende como contradictorio en un sentido fuerte. El contradictorio debe tener en cuenta valores de efectividad de tutela jurisdiccional, para lo cual debe regular no solo la relación entre las partes, sino también entre las partes y el juez. Cfr. PICARDI, Nicola, Manuale del processo civile (Milano, Giuffrè, 2006), pp. 210-211.

${ }^{34}$ Gentili, A., cit. (n. 27), p. 746.

${ }^{35}$ Garnica, J., cit. (n. 26), p. 1716.

${ }^{36}$ Véase: Serrano, Gregorio, La probibición de indefensión y su incidencia en el proceso (Granada, Editorial Comares), 1997, p. 88. 
Sin embargo, cuando se trata de la aplicación del Derecho, la extensión de la defensa suele ser algo cuestionada, precisamente por el rol del juez en relación al principio "iura novit curia" ${ }^{37}$. Se dice que la posición de las partes frente a las normas jurídicas es superflua, desde el momento en que el juez está en condiciones de conocerla e individualizarla gracias a su cualificación profesional y de los amplios instrumentos de indagación de los que goza. Su posición institucional y profesional condiciona la posición de las partes frente a los materiales jurídicos aplicables ${ }^{38}$. El juez tendría un rol preponderante en la aplicación de los materiales normativas, relegando a un segundo plano la actividad que puedan desarrollar los litigantes; éstos únicamente tendrían que aportar el marco inicial del debate jurídico satisfaciendo de esa forma la carga de la argumentación de la demanda.

Esta forma de entender el fenómeno jurídico de aplicación de los materiales normativos es excesivamente positivista y simplista, un modelo en el cual la norma jurídica es deducible casi mecánicamente de los hechos determinados de manera exacta e inequívoca ${ }^{39}$. La realidad, sin embargo, es otra. Hace bastante tiempo que se reconoce que los materiales normativos, como productos legislativos, no constituyen un dato fijo e inmutable, sino que están sometidas a un continuo devenir de valoración interpretativa, de formación creativa y de valide $z^{40}$. Esto significa que la tarea de aplicar las normas a los casos concretos es bastante compleja. Ni siquiera para el juez, con toda la libertad e instrumentos de que goza, está en condiciones de ofrecer una solución certera y segura del caso ${ }^{41}$.

${ }^{37}$ Trocker, N., cit. (n. 27), p. 64; y CAponi, Remo - Proto, Andrea, Lineamenti di diritto processuale civile (Napoli, Jovene, 2001), pp. 68-69. En este mismo sentido opina Gentili, A., cit. (n. 27), p. 752, quien indica que si bien el juez está vinculado a los límites de la demanda y la excepción, e incluso de la prueba, no lo está respecto a la propuesta jurídica de las partes. El contradictorio no sería, por esto, un principio necesario del razonamiento del juez respecto del Derecho aplicable. Véase además: GARNICA, J., cit. (n. 26), p. 1713, para quien la aplicación del derecho estaría fuera del poder de disposición de las partes. Véase, además, respecto de la inexistencia de incongruencia cuando el juez hace uso del principio "iura novit curia": Borrajo, Ignacio - DiezPicAzo, Ignacio - Fernández, Germán, El derecho a la tutela judicial y el recurso de amparo. Una reflexión sobre la jurisprudencia constitucional (Madrid, Civitas, 1995), p. 78; y Millán, C., cit. (n. 26), p. 97.

${ }^{38}$ Ezquiaga, F., cit. (n. 4), p. 17; y Hunter, I., cit. (n. 1), pp. 199-200.

${ }^{39}$ Trocker, N., cit. (n. 27), p. 643.

${ }^{40}$ Ibíd. Véase, además: PICARDI, Nicola, La funzione del giudice nell interpretazione e nell'applicazione del diritto, en Giustizia Civile, 53 (2003), pp. 363-364.

${ }^{41}$ Véase: Comanducci, P., cit. (n. 9), p. 129. Al respecto se dice que la determinación del contenido o significado de la norma depende, en gran parte, del criterio interpretativo que se utilice, y en ese sentido, es claro que puede existir una diversidad de significados en la medida que se empleen diversos criterios, con la consecuente difi- 
Hay que ser conscientes, además, que hoy asistimos un fenómeno denominado "hiperinflación legislativa", caracterizado por la creciente proliferación de cuerpos legales y normas singulares destinadas a la regulación de relaciones jurídicas específicas o más complejas ${ }^{42}$. Esta realidad ha producido una verdadera crisis de la ley, una fragmentación progresiva del ordenamiento jurídico, generando una casuística legislativa difícilmente conciliable con la generalidad, permanencia y abstracción de las normas jurídicas. Todo lo anterior trae como lógica consecuencia una fuerte dosis de inseguridad e incerteza jurídica al momento de fundamentar la pretensión, en la medida que resultan aplicables muchas normas conjunta o excluyentemente a la misma situación jurídica. Ciertamente esa imperfección del ordenamiento no debe ser soportada exclusivamente por el ciudadano, quien nada de "culpa o responsabilidad" tiene. El legislador debe ser consciente de estas falencias y crear las herramientas adecuadas para corregir las imperfecciones jurídicas relacionadas precisamente con esa incertidumbre e inseguridad.

En este contexto se hace fundamental conjugar el papel del juez con el de los ciudadanos que recurren a la jurisdicción. Si el ordenamiento está lejos de ser un todo orgánico, coherente y sistemático que facilite y garantice la protección de los derechos, no resulta justificable traspasar al ciudadano la carga de fundamentar correctamente la demanda. El abogado cumpliría una función de colaboración, necesariamente interesada, más no vinculante para el juez. Éste, por el contrario, tiene la misión de corregir esa imperfecta invocación de las normas jurídicas, y de remediar aquellos inconvenientes que el ordenamiento tiene para asegurar la tutela de los derechos de las personas.

Bajo esta perspectiva la función del letrado sería colocar la controversia en los parámetros jurídicamente correctos (fundamento jurídico), aunque no necesariamente exactos, suministrando al juez todos los argumentos jurídicos posibles para lograr una sentencia favorable. Un enfoque jurídico correcto, no solo relaja la pesada carga que tiene el tribunal al dictar sentencia, sino además aumenta las expectativas de lograr una sentencia que tutele los derechos e intereses de su cliente.

Si esto es cierto entonces la regla que tradicionalmente intenta sacar a las partes de toda participación relevante en la búsqueda del material jurídico no es exacta. La fundamentación de la demanda no vincula al tribunal, pero el abogado tiene el deber profesional de situar la controversia en los términos

cultad de definir el sentido y alcance la disposición concreta. Véase, además: MoRELL, Luis, El juez y la Administración, frente a los hechos y el derecho aplicable, en Cosculluela Montaner, Luis (coordinador), Estudios de Derecho público económico: libro homenaje al prof. Dr. D. Sebastián Martín-Retortillo (Madrid, Civitas, 2003), pp. 1414-1415.

${ }^{42}$ Hunter, I., cit. (n. 13), p. 207. 
que permita al juez, al menos, conceder el efecto jurídico pretendido. Se trata de un rol absolutamente indispensable y difícilmente sustituible, a menos que se quiera autorizar al juez para conceder un efecto distinto al solicitado en la demanda. De esta manera es posible afirmar que el abogado, como profesional conocedor del derecho, tiene la delicada misión de colaborar en la tutela de los derechos colocando la controversia jurídica en el marco jurídico correcto. Estando ahí, el juez es libre para aplicar el Derecho, argumentar y justificar su decisión, cuidando no lesionar el derecho de defensa del demandado.

\section{El PODER DE APLICACIÓN DEL DERECHO Y ALGUNAS CONSECUENCIAS PRÁCTICAS.}

\section{Concurso de normas y acciones, y aplicación judicial del Derecho.}

El concurso de normas y acciones es uno de los aspectos más controvertidos al momento de definir el alcance del poder del juez en la aplicación del Derecho. Se trata de una temática que al menos en nuestro país no ha sido lo suficientemente abordada, sin perjuicio que en el ámbito de la responsabilidad extracontractual suelen haber algunas referencias tangenciales. En el derecho comparado la situación tampoco es muy diversa. Es cierto que la definición de la norma que resulta aplicable a los hechos es una tarea que le corresponde definir al derecho material de acuerdo a ciertas pautas de interpretación. Sin embargo, cuando esos conflictos normativos (concursos) se deben resolver en un contexto judicial, las soluciones propuestas por la doctrina parecen no ser tan aplicables, al extremo de condicionar o morigerar la posibilidad de los tribunales de resolver la controversia conforme a la norma.

En líneas generales el problema de la aplicación del Derecho se presenta en hipótesis que podemos definir como simples: cuando la subsunción de un hecho cabe en una norma jurídica concreta que concede el efecto querido, al juez solo le cabe definir si esa subsunción es correcta, y obviamente, si los hechos que constituyen su presupuesto de aplicación han sido determinados en el juicio. Como lo explicábamos precedentemente este paso se ve en teoría sencillo, pero puede estar lleno de complicaciones relacionados con la validez de la norma, su interpretación, con la determinación de los presupuestos de hecho, etc. En otros casos será el mismo actor el que yerre en el fundamento jurídico de su demanda, sencillamente por torpeza o descuido, invocando una norma incorrecta o colocando como base de una pretensión un hecho que de acuerdo a las normas invocadas es irrelevante.

En ocasiones, sin embargo, la complejidad normativa del ordenamiento permite al ciudadano obtener el efecto jurídico deseado por distintos caminos, esto es, aplicando normas o estatutos jurídicos diferentes. En algunos casos, por medio del fenómeno que procesalmente se conoce como concurso 
de normas, y en otros, con la denominada concurrencia de acciones. En estas situaciones se plantea la disyuntiva de la extensión del poder del juez para aplicar el Derecho, y aunque la doctrina ha efectuado algunas construcciones teóricas al respecto éstas son insuficientes cuando quieren ser aplicadas en ordenamientos jurídicos concretos.

Conceptualmente hay concurso de acciones cuando "para unos mismos hechos, supuesta la identidad de fin, el Derecho puede abrir para su consecución una pluralidad de caminos; pero sólo porque los caminos no son iguales. Y como el mismo fin no puede obtenerse dos veces, elegido un camino (deducida una acción en juicio), quedan automáticamente cerrados los demás [...] no se trata de que un acaecimiento concreto pueda ser valorado bajo distintas normas diversas [...] sino de un supuesto de hecho que permite al actor efectuar en su demanda una petición delimitada en forma distinta" ${ }^{43}$. Siguiendo a Ortells, esta definición de concurso de acciones puede descomponerse de la siguiente forma: "1) unos hechos parcialmente idénticos o comunes; 2) la posibilidad de varias calificaciones jurídicas según los hechos diferenciales que sean destacados en la alegación; 3) la consecuencia jurídica derivada de los hechos es sólo una desde un punto de vista práctico o de utilidad, de modo que si el actor ve estimada su petición aduciendo una de las posibles configuraciones de la causa petendi, ni le interesa, ni puede obtener nueva tutela con base en las otras configuraciones de la causa petendi" ${ }^{4}$.

Como se puede observar el concurso de acciones se produce cuando dos o más normas jurídicas que permiten obtener el mismo efecto jurídico presentan hechos que parcialmente idénticos, existiendo, no obstante, otros supuestos fácticos diferentes. De esta manera el efecto jurídico deseado puede lograrse mediante la invocación de dos o más estatutos jurídicos que no pueden ser aplicados al mismo tiempo.

La doctrina señala que en este caso el juez no goza de ninguna clase de libertad puesto que se encuentra ligado por la acción efectivamente ejer-

${ }^{43}$ TAPIA, Isabel, La concurrencia de responsabilidad contractual y extracontractual. Tratamiento sustantivo y procesal, con Cavanillas Múgica (Madrid, Editorial Centro del Estudios Ramón Areces, 1995), p. 187; y Gómez, Emilio, Concurso de leyes y concurso de acciones en el Derecho civil, en Revista de Derecho Privado, 355 (1946), p. 711. También se conoce como concurso de derechos: véase Monteleone, Girolamo, Diritto processuale civile (Padova, Cedam, 2002), pp. 200 ss.

${ }^{44}$ Ortells, Manuel, Derecho procesal civil, (8 ${ }^{a}$ edición, Navarra, Editorial Thomson Aranzadi, 2008), p. 261. En Chile: Romero, Alejandro, Curso de Derecho procesal civil (Santiago, Editorial Jurídica de Chile, 2012), I, p. 81, con referencia jurisprudencial, entiende que existe concurso de acciones cuando "una misma situación de hecho puede estar amparada por una diversidad de acciones, que concurren a satisfacer el mismo interés del actor. En su esencia, se trata de acciones con causa de pedir diversa, aunque busquen el mismo fin jurídico o el mismo fin económico". 
cida por el ciudadano. Queda ligado y obligado a mover su decisión en el ámbito jurídico en que el actor ha querido situar su pretensión. Se dice que la razón de esta conclusión se produce porque "hay una clara manifestación de voluntad del justiciable al elegir uno de los tantos caminos que abre el ordenamiento para obtener el efecto deseado. Bajo esta perspectiva no puede el juez desvincularse de dicha elección y preferir otras aun cuando dote de eficacia a la tutela solicitada. El órgano jurisdiccional queda amarrado con la calificación y camino efectuado por el actor, y su vulneración no sólo implica un cambio en la causa de pedir (y por cierto, una incongruencia de la sentencia) sino desconocer la voluntad clara e inequívocamente manifestada de quien solicita la tutela" 45

La razón que se ha dado a esta limitación es que el cambio de la acción deducida provoca un cambio en el criterio de relevancia con que se han seleccionado los hechos. Cuando el juez se desvincula de la acción deducida están considerando relevantes hechos que si bien han sido introducidos en la demanda, no han querido ser colocados como base de la tutela por el actor. Así, por ejemplo, si un ciudadano ha celebrado un contrato de compraventa sobre un inmueble goza de dos acciones independientes para obtener la entrega material de la propiedad: la emanada del contrato de compraventa y la acción reivindicatoria por ser dueño sin posesión (en el evento, por cierto, de haberse efectuado la tradición) Si elige una de esas acciones entonces queda vedado para el juez pronunciarse por la otra por mucho que todos los hechos hayan sido efectivamente introducidos por las partes y que el objeto pedido se mantenga inalterado. En una se tutela un derecho de propiedad (en la reivindicación) en la otra un derecho emanado del contrato (en la de cumplimiento de contrato). La petición que se somete al tribunal se delimita en forma distinta en uno u otro caso ${ }^{46}$.

$\mathrm{Al}$ menos en la doctrina comparada el concurso de acciones aparece relacionado al principio dispositivo ${ }^{47}$, y con lo que, en un sentido técnico jurídico, corresponde a la alegación de un hecho. La diferencia entre una u otra acción vendrá determinada por la elección que haga el ciudadano res-

${ }^{45}$ Hunter, I., cit. (n. 28), p. 181; Ormazabal, G., cit. (n. 2), p. 54; y Berzosa, V, cit. (n. 26), p. 60. Así también: CAponi, R. - Рroto, A., cit. (n. 36), p. 59. Al respecto se entiende que en esta hipótesis existe una pluralidad de derechos sustanciales, de manera que si el ciudadano elige uno de ellos, el juez no puede dar aplicación al principio iura novit curia. Proto, Andrea, Lezioni di diritto processuale civile (Napoli, Jovene, 1999), p. 78.

${ }^{46}$ Berzosa, V., cit. (n. 26), pp. 58 y 60.

${ }^{47}$ TAPIA, I., cit. (n. 4), pp. 187-188, añade que: "esta distinta forma de delimitar la pretensión constituye precisamente el elemento causal del objeto litigioso, por lo que su variación o consideración distinta a lo largo del proceso provocaría, a mi juicio y como se verá más adelante, un cambio de demanda”. 
pecto de los hechos que diferencian las pretensiones. Y para ello es evidente que la invocación de los materiales jurídicos sí resulta crucial, pues son las normas aplicables las que permiten identificar los supuestos relevantes, y descartar cuáles hechos carecen de esa relevancia. En otras palabras, la elección del camino seguido por el ciudadano estará marcada no solo por los hechos sino además por las normas jurídicas. Con todo, también es posible que el actor, en la elección del camino y de la norma jurídica, pueda errar. Esto se produciría cuando de los hechos expuestos es posible inferir que el actor ha querido ejercer una determinada acción judicial, la que no se corresponde con las normas jurídicas invocadas. Por eso la elección debe ser clara y precisa.

Ahora bien lo que determinará la aplicación de régimen sobre otro será la relevancia con que la parte introduce los hechos. En este caso, el fundamento jurídico quedará delimitado por aquellos datos fácticos -solo aquellos- que según el actor permiten conceder el efecto jurídico. En cierta forma los materiales jurídicos invocados son los que determinan los hechos relevantes. El juez no podría, en principio, considerar otros hechos distintos como presupuesto de las normas aplicables. Por eso, sería importante que se dispusiera de alguna oportunidad procesal para que el juez pueda sugerir a las partes que determinado hecho indicado en la demanda ${ }^{48}$ pase a constituir la base de la pretensión y derivar las consecuencias jurídicas solicitadas. En cierta forma, lo que hace el juez es posibilitar que una determinada indicación de un hecho pase a la categoría de alegación de un hecho ${ }^{49}$, mediante la contradicción de las partes.

La otra posibilidad es que el legislador cree una regla similar al artículo 400 LEC. española $1 / 2000$, estableciendo una carga al actor de indicar en la demanda todos los fundamentos jurídicos que permiten obtener el efecto deseado. Me parece, sin embargo, que una regla como ésta no tutela adecuadamente los derechos de los ciudadanos, al mantenerse la posibilidad de que la parte omita inconscientemente un fundamento jurídico que pudo hacer valer en la demanda. Por eso, me inclino por la opción excepcional de abrir la posibilidad en la audiencia preliminar de extender las alegaciones.

Respecto del concurso de normas o leyes la doctrina está medianamente conteste en que el juez goza de una libertad plena al momento de aplicar las

\footnotetext{
${ }^{48}$ Cabe precisar que de acuerdo a lo sustentado hasta el momento, la expresión “indicación de un hecho" quedaría reservada a la exposición consciente de un determinado acontecimiento que hace un litigante en su demanda, pero sin atribuir algún contenido o valor jurídico específico. BUONCRistiani, D., cit. (n. 8), p. 26.

${ }^{49} \mathrm{El}$ paso se produce, por tanto, entre aquello que se entiende es la simple indicación de un hecho a lo que constituye la alegación en un sentido técnico jurídico, según ya tuvimos la oportunidad de señalar.
} 
normas jurídicas a los acontecimientos alegados por el actor ${ }^{50}$. $\mathrm{Al}$ respecto, y siguiendo a Berzosa Francos, "nos encontramos ante un concurso de leyes cuando entre dos normas, cuyo supuesto abstracto queda satisfecho por un mismo acaecer concreto, existe una relación tal, que una de ellas excluye la aplicación simultánea de la otra. El hecho se acomoda a las condiciones que en cada uno de los preceptos vienen descritas como causa del respectivo efecto" ${ }^{\text {I1 }}$. Otra parte de la doctrina agrega que no basta que un mismo supuesto de hecho sea reconducible a dos o más normas sino que es necesario que ese supuesto de hecho despliegue las mismas consecuencias jurídicas ${ }^{52}$. En otras palabras, existe concurso de leyes cuando un determinado acontecer de la realidad, que se incorpora como tal en la demanda, es posible adscribirlo a los supuestos de hecho abstractos de dos o más normas jurídicas, las cuales permiten obtener cada una por sí sola el efecto jurídico pretendido.

En este sentido la calificación jurídica que sustenta la pretensión de la parte no ligaría al juez, quien puede darle a los hechos la calificación que estime correcta. El juez no sólo puede sino además debe indicar las normas que el demandante haya omitido, omitir normas que se hayan señalado incorrectamente, corregir las mal formuladas, y salvar los yerros en la interpretación de las normas jurídicas. Al tratarse de supuestos que están ligados al conocimiento del Derecho que resulta aplicable, esto es, un problema de pura calificación jurídica de los hechos, pueden ser entregados libremente el juez ${ }^{53}$. Este sería un caso en que nuevamente las potestades de aplicación del Derecho del juez no aparecen recortadas por tratarse de una tarea esencial del ejercicio de la función jurisdiccional.

Se ha dicho que de la identificación de un concurso de normas emanan una serie de consecuencias prácticas, derivadas de esa libertad que se le reconoce al juez en la utilización de los materiales normativos: la primera, y aunque no es privativa de este supuesto, la parte no puede definir ni determinar el orden en que el juez deberá aplicar el Derecho, como tampoco pretender la aplicación de ambos estatutos ${ }^{54}$. Es al menos evidente que el juez deberá observar, en el contexto de la demanda, cuál ha sido el estatuto

${ }^{50}$ Berzosa, V., cit. (n. 26), pp. 56-57; TApia, I., cit. (n. 4), p. 199; Ormazabal, G., cit. (n. 2), p. 54. Millán, C., cit. (n. 26), pp. 57 y 58. Explica Proto, A., cit. (n. 44), p. 79, que esta libertad proviene de la idea de que el derecho sustancial es único, y en tal medida el juez puede elegir libremente el estatuto jurídico en el cual ese derecho puede ser tutelado.

${ }^{51}$ Berzosa, V., cit. (n. 26), p. 56. En similar sentido: Gómez, E., cit. (n. 43), p. 712.

${ }^{52}$ Tapia, I., cit. (n. 4), p. 199; y Ormazabal, G., cit. (n. 2), p. 54.

${ }^{53}$ Hunter, I., cit. (n. 27), p. 182; y TAPiA, I., cit. (n. 4), pp. 72.

${ }^{54}$ Berzosa, V., cit. (n. 26), p. 57. 
que el actor ha querido colocar como base en su pretensión, aunque lo haga de manera imprecisa e incluso incorrectamente ${ }^{55}$. $Y$ en segundo lugar, no puede considerarse una modificación de la pretensión el hecho de que en la demanda aparezca alegada y citada alguna norma jurídica, y posteriormente se cambie esa alegación o el juez termine aplicando otra ${ }^{56}$.

En el derecho sustantivo y en el ámbito de la responsabilidad civil suele hablarse de derecho de opción ${ }^{57}$, en el sentido que el lesionado puede elegir hacer efectiva la responsabilidad bajo algún estatuto jurídico específico. Es lo que ocurre, por ejemplo, con la responsabilidad que emana de los daños en la construcción, donde la doctrina ha estimado que el perjudicado puede elegir entre el régimen general del Código Civil (artículos 2003, 2004 y 2324 CC.) o el especial de la Ley de urbanismo y construcción (artículos 18 y 19 LGUC.), aunque también se indica que no pueden mezclarse las disposiciones de ambos regímenes ${ }^{58}$. Se trata de casos en que para conseguir un fin (la indemnización de perjuicios) resultan aplicables diferentes normas al mismo supuesto fáctico (CC. y LGUC.), pudiendo escogerse cualquiera de ellas.

Con todo, esta pretendida libertad del juez para la aplicación de los textos normativos no es tan real cuando la enfrentamos a situaciones concretas. En primer lugar porque si el concurso de leyes se asume como un caso de opción para el damnificado, el que podrá elegir entre uno u otro estatuto, resulta al menos cuestionable que el juez pueda flanquear esa elección estableciendo la aplicación de otras normas jurídicas ${ }^{59}$. Sucede además que la aplicación de uno u otro estatuto en la sentencia definitiva puede colocar en riesgo la defensa del demandado, quien confiado en la aplicación de un estatuto, no alegó una defensa o excepción propia del otro. En el ejemplo utilizado sería el caso de una prescripción extintiva o alguna defensa derivada de la distinta naturaleza de los regímenes de responsabilidad, puesto que en la Ley General de Urbanismo y Construcción se establecen plazos especiales que difieren del plazo general del Código Civil. El paso de un estatuto otro podría generar una situación de indefensión. Por esto es que, nuevamente, la

${ }^{55}$ Comoglio, Luigi, La domanda giudiziale, Rivista Trimestrale Diritto e Procedura Civile 62 (1988), p. 1303.

${ }^{56}$ Berzosa, V., cit. (n. 26), p. 57.

${ }^{57}$ Corral, Hernán, Responsabilidad civil en la construcción de viviendas. Reflexiones sobre los regímenes legales aplicables a los daños provocados por el terremoto del 27 de febrero de 2010, en Revista Chilena de Derecho, 3 (2010), p. 460.

${ }^{58}$ Véase, por todos: Corral, H., cit. (n. 56), p. 460; y BArros, Enrique, Tratado de responsabilidad extracontractual (Santiago, Editorial Jurídica de Chile, 2007), p. 772.

${ }^{59}$ Esta posibilidad podría darse únicamente en el caso en que la parte yerre en indicar el estatuto jurídico que desea utilizar siendo que de la demanda se desprende inequívocamente que es otro. 
contradicción y la posibilidad de ampliar la defensa del demandado cuando el juez observe que será necesaria la aplicación de otras normas distintas a las invocadas resultan esenciales para observar un proceso justo, sustantiva y procedimentalmente. Solo la contradicción previa habilitará al juez para escoger libremente la norma aplicable en el caso del concurso de leyes cuando el actor yerra en su elección ${ }^{60}$.

La segunda objeción, que se acopla a la anterior, es el contexto en que se produce la aplicación de las normas jurídicas, esto es, en un proceso judicial concreto. Al menos en nuestro país existe un patrón común o base para el conocimiento de la mayoría de las controversias, que es el proceso ordinario. Sin embargo, muchas de las normas que alternativamente pueden resultar aplicables tienen asignado un procedimiento especial, y en más de alguna oportunidad, la aplicación de ellas solo las puede hacer un tribunal especial. Este es el caso, por ejemplo, de la responsabilidad del fabricante por productos defectuosos. La doctrina del Derecho Civil está dividida respecto al estatuto que puede aplicarse al fabricante para hacer efectiva su responsabilidad ${ }^{61}$. Para algunos resulta aplicable la Ley de protección a los derechos del consumidor en su artículo 23, mientras que para otros el régimen general de responsabilidad civil extracontractual. Ciertamente se trata de un caso típico de concurso de normas, donde los supuestos fácticos del caso concreto son reconducibles a dos normas jurídicas diferentes que conceden idéntico efecto jurídico: la indemnización de perjuicios. En este supuesto, sin embargo, la aplicación del derecho se da en un contexto judicial absolutamente determinante: en un caso, es el Juzgado de Policía Local el encargado de hacer efectiva la responsabilidad, mientras que en el otro son los tribunales ordinarios. De esta forma un tribunal civil ordinario no podría aplicar las normas del consumo

${ }^{60}$ Indica Hunter, Iván, La aplicación judicial del derecho y la motivación de la sentencia en el PCPC, en Cuadernos de Extensión Jurídica, 23 (U. de los Andes, 2012), p. 170 , un aspecto adicional y que dice relación con el alcance del deber de motivación en el caso de concurso de normas. Explica que "más allá de la norma concreta que pueda resultar aplicable, el tema es mucho más amplio pues esa libertad de elección normativa que tiene el juez no está exenta de justificación (esto es, requiere ser motivada y justificada), más aún cuando cambiar la norma aplicable puede significar modificar el estatuto jurídico que disciplina la relación jurídica material. Aquí es importante que el juez exponga las razones que justifican la aplicación de una norma por sobre la otra, y concretamente presente argumentos para justificar las particularidades jurídicas que permiten adscribir a la relación jurídica material objeto de la litis a un determinado estatuto jurídico".

${ }^{61}$ Para un panorama completo: BARRIEnTos, Francisca, La responsabilidad civil del fabricante bajo el artículo 23 de la ley de protección de los derechos de los consumidores y su relación con la responsabilidad civil del vendedor, en Revista Chilena de Derecho Privado, 14 (2010), pp. 109-158. 
por estar situadas en la competencia material de otro tribunal de justicia. Y al mismo tiempo, un Juez de policía local no podría aplicar el régimen general de responsabilidad extracontractual puesto que su determinación -salvo los casos expresamente señalados por la ley-debe definirla un juzgado civil.

Con este ejemplo la pretendida libertad de los jueces en la aplicación del Derecho cuando se trata del concurso de normas es más aparente que real, y coloca en serios aprietos al legislador al momento de definir una infinidad de procedimientos y de competencias jurisdiccionales para relaciones jurídicas materiales jurídicamente complejas.

\section{Modificación de la demanda y aplicación del Derecho.}

Para nadie es novedad que la demanda constituye uno de los momentos más trascendentales del proceso civil. A través de ella no solo se ejercita el derecho de acción y se condiciona el ejercicio del poder jurisdiccional, sino también se fijan los límites objetivos y subjetivos del deber de pronunciar una sentencia sobre el mérito ${ }^{62}$.

Respecto de la posibilidad de modificar ${ }^{63}$ la demanda también pueden encontrarse algunas repercusiones en relación al alcance del poder del juez para aplicar el Derecho. Si el tribunal decide aplicar un estatuto jurídico distinto al que se contiene en la demanda implícitamente la está modificando, puesto que las normas, fundamento o calificación jurídica que sustenta la condena se aparta del contenido inicial de la pretensión ${ }^{64}$. Es cierto que nunca se ha exigido una identidad completa entre demanda y sentencia ${ }^{65}$, pero es

${ }^{62}$ Comoglio, L., cit. (n. 54), p. 1302.

${ }^{63}$ Utilizo la expresión modificación como sinónimo de enmienda o corrección de la demanda, y no como cambio de ella. En el derecho comparado es frecuente la dicotomía entre mutatio y emendatio de la demanda. Cfr. Verde, Giovanni, Profili del proceso civile, Parte generale (Napoli, Jovene, 1988), p. 92; Comoglio, L., cit. (n. 54), p. 1307; y TARuffo, Michele, Le preclusioni nella reforma del proceso civile, en Rivista di Diritto Processuale, 1 (1992), p. 301.

${ }^{64}$ Esta conclusión puede ser resultado de un proceso algo complejo. ComogLio, L., cit. (n. 54), p. 1303, explica que la exigencia hacia el juez en relación al contenido de la demanda no está relacionado con la búsqueda de la intención o voluntad interna del actor al estilo de un contrato, como tampoco puede contentarse con una determinada formulación de su tenor literal. Más bien mira a una indagación objetiva del significado funcional que la demanda debe tener en el contexto de las alegaciones enunciadas por la parte, teniendo en cuenta las relaciones entre situación subjetiva deducida en juicio y el tipo o clase de tutela jurisdiccional a la que razonablemente se aspira.

${ }^{65}$ Gómez, Emilio, Derecho procesal civil, Parte general: Proceso declarativo (Madrid, Artes Gráficas y Ediciones, 1979), p. 215, opina que la demanda contiene un "proyecto de sentencia”, lo que hace entender que el juez debería encontrar en el cuerpo de la demanda los antecedentes, al menos esenciales, para dictar una sentencia favorable a los intereses del actor. 
exigible la existencia de algunos elementos jurídicos que hagan reconocible a la demanda en la sentencia. De esta forma parece necesario conjugar la posibilidad del juez de apartarse de los elementos jurídicos que sustentan la pretensión con la facultad de las partes de modificar el estatuto jurídico aplicable a la demanda.

Quisiera partir de una idea central. No resulta justificable que un sistema procesal impida a las partes alterar el estatuto jurídico que contiene la demanda, estableciendo su carácter inmutable, pero a la vez permita que tal modificación la efectúe el juez en la sentencia definitiva, apartándose de la fundamentación jurídica que la sostiene, y muchas veces, poniendo en jaque el derecho de defensa de la parte demandada. Parece más coherente un sistema que articule oportunidades para actuar simultáneamente los poderes del juez con las facultades de las partes, racionalizando la utilización de las preclusiones en la etapa de preparación del objeto de la controversia ${ }^{66}$.

Es cierto que el interés primario del legislador es garantizar la estabilidad de los hechos alegados y de los fundamentos jurídicos. Sin embargo, los sistemas procesales modernos suelen incluir momentos para que el actor pueda modificar la demanda, y más concretamente, el Derecho invocado en la misma. La primera oportunidad, casi sin limitación, es antes que ésta haya sido contestada, donde se pueden introducir cambios objetivos o subjetivos que estime pertinentes, incluyendo obviamente, el estatuto jurídico que estima aplicable a la relación jurídica. Ese el caso del artículo 257 PCPC. que permite a las partes libremente modificar la demanda antes de su contestación, con las distinciones y consecuencias que para cada caso la norma indica. Sin embargo, esta norma no permite solucionar la cuestión de fondo. Tampoco la norma del artículo 276 PCPC., que permite a las partes en la audiencia preliminar complementar las alegaciones sin que se pueda alterar el efecto principal del pleito ${ }^{67}$, soluciona la cuestión de fondo.

${ }^{66} \mathrm{La}$ preclusión consiste en la pérdida, extinción o consumación de una facultad procesal. Produce solo efectos endoprocesales impidiendo que los puntos ya decididos puedan ser deducidos ex novo al interior del proceso. Véase: LANDI, Pasquale, Il processo civile come conoscenza logica, en Rivista Trimestrale di Diritto e Procedura Civile, 62 (1988), p. 1223. Los sistemas procesales modernos suelen introducir preclusiones más o menos rígidas, por lo general después de la preparación preliminar de la causa. Se considera que la causa queda mejor preparada y las partes desarrollan de mejor forma sus defensas si la fase preparatoria no está detalladamente regulada y no contiene muchas preclusiones dentro de ella. Parece razonable, por el contrario, que cuando la preparación de la causa está terminada, y las partes han tenido amplias posibilidades de articular (incluso modificando e innovando) las respectivas posiciones, el proceso deba concluirse mediante una preclusión rígida, quedando así definido el objeto de la controversia. Véase TARUffo, M., cit. (n. 61), p. 297.

${ }^{67}$ Esta fórmula equivale, hasta cierto punto, al objetivo actual de los escritos de 
El escollo real se produce por el silencio legislativo acerca de la posibilidad de modificar la demanda una vez que ha existido contestación a la demanda y la litis queda trabada.

Hay consenso en que las partes podrían modificar el nomen iuris de la pretensión deducida, como también las normas jurídicas citadas en la demanda e incluso el punto de vista jurídico siempre que se mantengan incólumes los hechos que justifican la petición de tutela ${ }^{68}$, dado que no constituyen elementos centrales ni definitorios del pleito. En la medida que se mantengan los hechos y el fundamento jurídico, cambiar la denominación de la pretensión o las normas que estimaban aplicables no altera el objeto del proceso o la congruencia de la controversia.

Otra cuestión, por cierto, es si esta modificación puede extenderse a los fundamentos o calificación jurídica, y más concretamente, al estatuto jurídico que resulta aplicable a la relación jurídica. No se trata de modificar lo que entendemos por fundamentación jurídica, sino de adscribir los hechos a otro estatuto que permite conceder el efecto jurídico pretendido. En general se entiende que el órgano jurisdiccional es un completo dominador de los materiales jurídicos que resultan aplicables a la relación jurídica; si el juez puede efectuar esa modificación también podrían hacerlo las partes ${ }^{69}$.

réplica y dúplica, en que el actor o demandado pueden modificar, adicionar o ampliar las acciones y excepciones sin alterar las que son objeto principal del pleito. $\mathrm{Al}$ respecto la jurisprudencia ha acudido a la antigua tesis de la causa de pedir para efectos de determinar si el actor o demandado pueden modificar la calificación jurídica de la acción o excepción. Así se demuestra en un fallo de la Corte Suprema de 11 de noviembre de 1931, que indicó: "La circunstancia de que en la réplica se diga que se incurrió en un error en la demanda al calificar como sociedad mercantil el contrato a virtud del cual se cobra una participación, siendo que se trataba de una sociedad civil o, por lo menos, de otro contrato, cualquiera que sea su calificación, por lo cual adiciona la demanda en este sentido, no importa una modificación que implique cambio alguno en la acción deducida, porque, permaneciendo unas mismas la cosa pedida y las personas que intervinieron en la litis, las acciones se caracterizan, individualizan o identifican por los hechos que le sirven de fundamento o causa de pedir, y tales hechos no resultan alterados o modificados por la sola circunstancia de que el actor los califique juridicamente en la réplica en forma distinta de como los apreció en la demanda" (Corte Suprema, sentencia de 11 noviembre 1931, en Revista de Derecho y Jurisprudencia, 29, sec. $1^{a}$, p. 167. También puede verse: Corte de Apelaciones de Santiago, sentencias de 8 julio 1941, en Revista de Derecho y Jurisprudencia, 39, sec. $2^{\text {a }}$, p. 41; de 8 julio de 1941, ibíd., 39, sec. $2^{\text {a }}$, p. 41; y de 10 junio 1942, ibíd., 39, sec. $2^{\circ}$, p. 77). Así, de acuerdo a la jurisprudencia, el actor o demandado posee una amplia facultad para modificar la calificación jurídica de las acciones y excepciones, siempre que mantenga incólume los hechos que fundamentan la demanda.

${ }^{68}$ Picó i Junoy, Joan, La modificación de la demanda en el proceso civil (Valencia, Tirant lo Blanch, 2006), p. 30-31; y TAPIA, I., cit. (n. 4), p. 73.

${ }^{69} \mathrm{Al}$ menos para la jurisprudencia española la posibilidad de que las partes modi- 
A esta posibilidad, no obstante, suele agregarse una limitación: el cambio en el punto de vista jurídico no puede alterar los hechos integrantes de la causa de pedir ${ }^{70}$. Esta respuesta, no obstante, es insatisfactoria.

Siempre se ha dicho por la doctrina que los hechos relevantes en el juicio son aquellos que permiten conceder el efecto jurídico pretendido. Son los que técnicamente se conectan con la alegación. También se afirma que no todos los hechos expuestos en la demanda son manifestación del principio dispositivo, sino únicamente los denominados principales, en oposición a otros que son los secundarios o motivadores. Ello supone que existen otros hechos incorporados en la demanda que carecen de relevancia en la medida que no permiten conceder el efecto jurídico solicitado. Estas afirmaciones son correctas, pero presentan una visión parcial del problema.

No son pocos los casos en que los hechos expuestos en una demanda permiten alcanzar el efecto jurídico pretendido aplicando estatutos jurídicos absolutamente contradictorios. Por ejemplo, el ciudadano que solicita una indemnización de perjuicios invocando las normas extracontractuales, no obstante, indicar en la demanda la existencia de un vínculo jurídico previo con el demandado. La decisión de invocar uno u otro estatuto jurídico dependerá de la relevancia con que el actor introduzca los hechos. Así, la alegación de una responsabilidad extracontractual hará jurídicamente irrelevante la existencia del contrato. El fundamento jurídico de la responsabilidad será el hecho que el actor entiende le da origen. El límite entonces queda definido por el respeto de los hechos que el actor ha querido situar en la base de su pretensión y colocar como jurídicamente relevantes. De esta forma, si la modificación de la demanda se refiere a los puntos jurídicos que la sustentan, ésta no puede alterar la relevancia de los hechos introducidos por las partes. Mediante la modificación de la demanda no puede hacerse jurídicamente relevante un hecho que en principio no lo fue $\mathrm{e}^{71}$.

fiquen los extremos jurídicos de la controversia contenidos en la demanda se explica en la actuación de la máxima iura novit curia. Las partes podrían variar el fundamento jurídico de la demanda en tanto éste no forma parte del objeto del proceso ni de la causa de pedir. Si el juez es libre para la aplicación del derecho, con mayor razón las partes, quienes sostienen la pretensión en juicio, pueden modificar el contenido jurídico de la controversia. Véase TAPIA, I., cit. (n. 4), pp. 71-72.

${ }^{70}$ Véase, por todos: Morón, Manuel, Derecho procesal civil (Cuestiones fundamentales) (Madrid, Marcial Pons, 1993), p. 252. De esta conclusión deriva otra igual de relevante: la estrecha conexión entre los hechos y la aplicación de la norma, cuestión que sepulta la pretendida separación que con cierta frecuencia suele encontrarse en la jurisprudencia nacional y comparada. Serían los hechos los que definen las normas jurídicas que se estiman aplicables. Sobre esto y la anterior limitación, véase: EzQUIAGA, F., cit. (n. 4), pp. 63 ss., y pp. 54-57.

${ }^{71}$ Explica Verde que si la parte ha puesto como base del efecto jurídico un determi- 
Puede decirse que existen valores en evidente tensión: por un lado, es efectivo que criterios de certeza y seguridad jurídica abogan por un sistema rígido de modificación de la demanda, en la medida que las partes deben saber desde el inicio el ámbito fáctico y jurídico de la controversia, con la finalidad de que organicen de modo adecuado la defensa y planifiquen sus esfuerzos probatorios $^{72}$. Por otro lado, aceptar un sistema estricto de modificación de la demanda puede terminar con resultados injustos, dado que somete la efectividad de la tutela judicial de los derechos e intereses a la capacidad del litigante -su abogado- de acertar en los materiales jurídicos aplicables. No hay que olvidar que los supuestos en que la modificación de la demanda se hace necesaria están relacionados con casos en que el actor ha equivocado respecto del hecho que ha querido situar como base de su pretensión, colocando a otro como jurídicamente relevante, conduciendo al rechazo, por ese solo motivo, la demanda. Esa razón explica que en prácticamente todos los sistemas procesales la iniciativa en la modificación de la demanda le corresponda a las partes.

La opción que se adopte respecto de esta institución deberá conjugar la concepción que se tenga acerca de la función de la jurisdicción y el rol legitimador de la contradicción para la decisión justa. Lo ideal en un sistema judicial, preocupado de la tutela judicial efectiva de los derechos de las personas, es que constatada la titularidad y lesión de un derecho e interés legítimo el tribunal pueda brindar la protección requerida, sin que la incorrecta invocación de las normas sea un obstáculo. Para cristalizar estas ideas podría ser necesario que las partes modifiquen la demanda cuando ellas se percaten que el estatuto jurídico está incorrectamente invocado, alterando el criterio de relevancia con que han introducido los hechos. Se trata, por tanto, de algo que ya veníamos mencionando: la posibilidad de pasar de la simple indicación de un hecho a la alegación del mismo, esto es, un dato fáctico pasa de ser secundario a principal, de ser irrelevante para efectos de la calificación, a ser el hecho que determina las normas que resultan aplicables.

Esta modificación no puede afectar la congruencia del proceso, y distraer la discusión y prueba hacia otros extremos. Por eso resulta razonable que en

nado hecho y el juez considera que ese efecto se justifica en base a otro hecho que aparece del proceso no puede sustituirlo, salvo los casos en que está autorizado a actuar de oficio. El juez tampoco puede sustituir a la parte en la derivación de las consecuencias jurídicas requeridas a partir del establecimiento de un determinado dato fáctico. Cfr. VERDE, G., cit. (n. 61), p. 94. En el mismo sentido: RiccI, Gian, L'allegazione dei fatti nel nuovo processo civile, en Rivista Trimestrale di Diritto e Procedura Civile, 3 (1992), p. 855; Comogrio, L., cit. (n. 54), p. 1304, quien indica que toca a la alegación en sentido estricto hacer de límite para la plena vigencia del iura novit curia.

${ }^{72}$ TAPIA, I., cit. (n. 4), p. 72. 
la audiencia preliminar las partes puedan modificar la demanda en todos los aspectos jurídicos relevantes, alterando el criterio de relevancia con que se introducen los hechos al proceso, siempre que no se modifique el efecto jurídico pretendido ${ }^{73}$.

Esta facultad consistiría en situar un hecho (o conjunto de hechos) previamente incorporados en la demanda -en principio secundarios o irrelevantes para justificar la aplicación de una norma-, como base de la pretensión, y cuya determinación verdadera justifica el efecto jurídico deseado por el actor. La alteración del criterio de relevancia no significa que el demandante pueda introducir (alegar) otros hechos a la litis para cambiar el estatuto jurídico aplicable, puesto que ello equivaldría a cambiar la demanda, lo que en ningún ordenamiento, incluso en los más flexibles, está permitido ${ }^{74}$. Con esto se supera la clásica limitación de no modificar los hechos que integran la causa de pedir, la que además de ser especialmente dificultosa de definir en el plano teórico y más aun en el práctico, no tiene una consagración expresa en el PCPC. Además organiza un sistema de preclusiones algo más flexible, puesto que la sola interposición de la demanda no extingue la posibilidad de modificar su contenido normativo, haciendo posible la conjugación de las exigencias de certeza y seguridad con la justicia que legitima la decisión jurisdiccional.

Esta circunstancia, sin embargo, puede llegar a afectar la defensa del demandado, que es organizada en relación a los fundamentos fácticos y jurídicos presentados en la demanda. La estrategia de las partes se ordena y define de acuerdo a los antecedentes jurídicos esgrimidos en la pretensión y modificarlos sustancialmente puede significar lesionar el derecho de defensa ${ }^{75}$. Un cambio en el punto de vista jurídico contenido en la demanda puede afectar la defensa no solo porque pueden existir ocasiones en que ésta

${ }^{73}$ Hunter, I., cit. (n. 13), p. 219; Verde, G., cit. (n. 61), p. 94; Ormazabal, G., cit. (n. 2), pp. 126 y 127. Con todo, un sistema mixto sería el italiano donde la enmienda de la demanda debe ser autorizada por el juez, previa petición razonada de la parte. Con este mecanismo se evita que las partes introduzcan modificaciones de manera libre a la demanda, o sea, sin el señalamiento de buenas razones. No existe consenso en la doctrina respecto de esta posibilidad. Véase: TARUfFo, M., cit. (n. 61), p. 302.

${ }^{74}$ Picó i Junoy, J., cit. (n. 68), pp. 50 ss.; y Comoglio, L., cit. (n. 54), p. 1307. Con esto además se resuelve la dificultad práctica, constada por la doctrina, de diferenciar la modificación con el cambio de la demanda, con todos los problemas relacionados con la incerteza de la distinción. TARUfFo, M., cit. (n. 61), p. 301.

${ }^{75}$ Picó i Junoy, J., cit. (n. 68), pp. 50-55; Tapia, I., cit. (n. 4), p. 72; y Prieto, L., cit. (n. 3), pp. 254 y 260. Puede consultarse en relación a cuándo una alteración importa un cambio de la demanda: Grasso, Eduardo, Note sui poteri del giudice nel nuovo proceso di cognizione in primo grado, en Rivista di Diritto Processuale, 3 (1992), pp. 717-718. 
se ha estructurado únicamente en la incorrección de los materiales jurídicos invocados ${ }^{76}$, sino además porque la modificación de las normas jurídicas aplicables termina repercutiendo en la relevancia de los hechos que tienen que ser objeto de la prueba. Por eso, es razonable que se le confiera al demandado la posibilidad de reorganizar su defensa, disponiendo de una oportunidad para contradecir la nueva adscripción de los hechos alegada por el actor, fundar nuevas defensas o excepciones, y por último, agregar los hechos que estime pertinentes en relación a la nueva calificación propuesta por el actor ${ }^{77}$. Obviamente, esta facultad debe ir acompañada de la posibilidad de ampliar el ofrecimiento probatorio contenido en la demanda y contestación, pues los esfuerzos probatorios deberán extenderse a hechos que en principio eran irrelevantes desde el objeto de la prueba.

Sin profundizar más de lo que antes se intentó, es claro que la contradicción, en todo el sentido técnico de la expresión, juega el papel de vaso comunicante entre la justicia procedimental, que exige el pleno respeto a las garantías procesales de los justiciables, y la justicia sustancial, que impone a los jueces la función de tutelar efectivamente los derechos de los ciudadanos.

\section{La cosa juzgada y la aplicación judicial del Derecho.}

Otro de los aspectos en que suele ser relevante un estudio del alcance de los poderes del juez en la aplicación del Derecho es en la cosa juzgada. El problema que se baraja en esta hipótesis es sencillo, pero absolutamente relevante: ¿la identidad fáctica pero no jurídica entre dos pleitos hace procedente la excepción de cosa juzgada?

La respuesta a esta interrogante tiene que venir necesariamente precedida de dos ideas: la primera es que en el marco del PCPC. se abandona la clásica exigencia de la triple identidad para determinar si entre dos procesos existe cosa juzgada; por el contrario, se utiliza una tesis que ha sido sustentada por

${ }^{76}$ Por esta razón es que entiendo que los poderes del juez en la aplicación del Derecho deben quedar lo suficientemente claros en el plano dogmático. Si ambos litigantes saben que el juez podrá corregir los aspectos jurídicos de la pretensión es natural entender que no habrá un gran incentivo en estructurar la defensa alegando cuestiones exclusivamente jurídicas. Pero si ese poder del juez queda entregado al operador de turno, pueden suceder situaciones injustas, como que el demandado fundamenta su defensa en la errada calificación jurídica de los hechos que hace el actor, quien después la corrige o enmienda teniendo presente la contestación de la demanda.

${ }^{77} \mathrm{La}$ articulación de un contradictorio como parte del juego dialéctico que debe producirse entre quienes sustentan intereses contrapuestos es el mejor instrumento y más fácilmente utilizable para que el juez pueda recoger el material necesario para la dictación de una sentencia más justa, aun en los extremos que parecen más ligados a la actividad del juez como es la aplicación de las normas jurídicas. Véase Verde, G., cit. (n. 61), p. 96; y Trocker, N., cit. (n. 27), p. 682. 
la doctrina más moderna, en el sentido que existiendo identidad de sujetos, lo relevante es determinar si concurren ciertos elementos de identidad entre ambos procesos, con la finalidad de impedir la dictación de sentencias contradictorias y el inicio de procedimientos que versen sobre materias en que ya ha recaído sentencia ejecutoriada ${ }^{78}$. Hoy en día se afirma con absoluta nitidez que la identidad total entre dos pleitos resulta prácticamente imposible, y que a lo más se puede optar a una similitud entre los objetos de los dos jui$\operatorname{cios}^{79}$. Aquí la tarea del juez va ser fundamental, puesto que le corresponderá definir, desligado de reglas precisas que orienten su decisión, cuándo una controversia ha sido precedida por un pronunciamiento judicial que ya la resolvió definitivamente. En lo que nos atañe, el juez decidirá si la diversidad en los materiales jurídicos o fundamento jurídico que sustentan una u otra demanda permiten justificar la existencia de dos pleitos diferentes.

En segundo lugar, otro aspecto relevante, también relacionado con la cosa juzgada, es la aplicación de la denominada "cosa juzgada virtual", que si bien ha tenido las más importantes repercusiones en el Derecho comparado europeo (especialmente en España), de igual forma encuentra manifestaciones y acogida en nuestro ordenamiento ${ }^{80}$. En virtud de ésta el pronunciamiento judicial no sólo cubriría lo efectivamente deducido y resuelto por el tribunal, sino además todo aquello que pudo hacerse valer en el pleito anterior aunque no se haya hecho ${ }^{81}$. El problema surge en la medida que se quiera extender los efectos de la cosa juzgada al nuevo pleito en que se invocan argumentos

${ }^{78}$ El "Mensaje" con que el ejecutivo despacha el PCPC. señala con precisión lo siguiente: "Asimismo, en materia de cosa juzgada, recogiendo las tendencias modernas en esta materia, se regula su efecto positivo o prejudicial, e innovando en lo que ha sido tradicional, se elimina la triple identidad como factor determinante para la configuración de la fase negativa de este instituto. Se mantiene, como es indispensable, la identidad subjetiva, pero se entregan los demás elementos al análisis identitario que efectúe razonadamente el tribunal, con el fin de impedir la dictación de sentencias contradictorias y el iniciar procesos que versen sobre asuntos ya decididos por sentencias ejecutoriadas".

${ }^{79}$ Nieva, Jordi, La cosa juzgada. El fin de un mito (Santiago, Legalpublishing, 2010), p. 45.

${ }^{80}$ Véase: Romero, Alejandro, La cosa juzgada en el proceso civil chileno. Doctrina y jurisprudencia (Santiago, Editorial Jurídica de Chile, 2002), pp. 68-71, con referencia jurisprudencial.

${ }^{81}$ Véase: TAPIA, I., cit. (n. 4), pp. 156 y 157. En este trabajo solo expondré de modo muy resumido esta temática, pues con la nueva regulación contenida en la Ley $\mathrm{N}^{\circ}$ 1/2000 LEC se han presentado una serie de inconvenientes que tienen a la doctrina en franca imposibilidad de llegar a un acuerdo. Por de pronto, señalaré que el concepto de "deducible pero no deducido" genera bastantes problemas de delimitación, más de los deseados para una institución que produce importantes consecuencias jurídicas sobre los derechos de los ciudadanos. 
jurídicos (fundamentación) distintos a los que se resolvieron en el pleito anterior.

Quisiera empezar con lo que entiendo es más sencillo, o al menos que no genera mayor discusión. Es razonable entender que la cosa juzgada produce un importante efecto preclusivo sobre la argumentación jurídica, en el sentido que la fundamentación de una pretensión que no se hizo valer en un pleito no puede alegarse para uno posterior ${ }^{82}$. Prácticamente serían inagotables los procesos si se permitiese a las partes invocar sucesivamente la tutela jurisdiccional alegando nuevos argumentos jurídicos, lo que atentaría contra la certeza y economía procesal. Por eso es natural entender que la cosa juzgada despliega sus efectos tanto sobre los argumentos jurídicos efectivamente alegados como sobre aquellos en que sin ser alegados pudieron serlo ${ }^{83}$. Como explica muy bien la doctrina todo lo que tribunal puede hacer en virtud del principio "iura novit curia", si se hace valer por el actor en un nuevo proceso operará la preclusión y se encontrará cubierto por los efectos de la cosa juzgada recaída en el proceso anterior ${ }^{84}$. En palabras concretas, como la fundamentación jurídica es algo que el juez puede realizar sin mayor limitación ${ }^{85}$, los nuevos argumentos quedarán absorbidos por la sentencia primitiva.

${ }^{82}$ Silguero, Joaquín, La preclusión de alegaciones en el proceso civil (Pamplona, Thomson Reuters, 2009), pp. 89 y 133, quien indica se trataría de una suerte de preclusión mixta o intermedia. Véase, además: TAPIA, I., cit. (n. 4), p. 156, quien indica que no cabe la posibilidad de plantear en el nuevo pleito argumentos que habría podido ser esgrimidos en el pleito anterior. También TAPIA, I., La cosa juzgada (Estudio de jurisprudencia civil) (Madrid, Dykinson, 2010), p. 109. Para la doctrina italiana: LANCELlottт, Franco, Variazioni dell'implicito rispetto alla domanda, alla pronuncia ed al giudicato, en Studi in memoria di Salvatore Satta (Pavia, Cedam, 1982), p. 742.

${ }^{83} \mathrm{Si}$ los argumentos jurídicos del proceso nuevo pudieron ser invocados por el actor en el proceso anterior entonces hay cosa juzgada virtual o preclusión, si se quiere. $\mathrm{Al}$ contrario, si los argumentos jurídicos no tenían cabida en el proceso anterior no es posible afirmar la procedencia de la cosa juzgada implícita, aun cuando los hechos sean los mismos. Como se puede apreciar se trata de un aspecto teóricamente sencillo, pero de tremendas dificultades prácticas. Al respecto, Véase: PADURA, T., cit. (n. 3), p. 80.

${ }^{84}$ PÉrez, Jacinto, La regla de la preclusión del artículo 400 de la Ley de Enjuiciamiento Civil, en Revista del Poder Judicial, 78 (2005), p. 187. En esta clase de elementos sí cabe predicar, en toda su extensión, el principio de eventualidad, estableciendo un sistema rígido de preclusiones. Véase: DE SANTIS, Francesco, Riforme processuali e "disponibilità" del regime preclusivo, en Rivista di Diritto e Procedura Civile, 4 (2004), p. 1261.

${ }^{85}$ Se dice con acierto que la exigencia de congruencia que tiene el juez es con la demanda y la contestación pero no con los razonamientos jurídicos, siendo libre para fundamentar su fallo en argumentos no alegados ni debatidos por las partes. Véase: YLlesCA, R., cit. (n. 4), p. 830. 
La solución propuesta es evidentemente muy sencilla aunque puede presentar innumerables inconvenientes prácticos. En ocasiones será muy difícil establecer una distinción clara y rotunda entre fundamento y argumentación jurídica, siendo vital la tarea que pueda desarrollar el juez, y la justificación que pueda realizar al respecto. Tampoco operarán los efectos preclusivos de la cosa juzgada en las hipótesis de concurso de acciones. Cuando el actor ha invocado un fundamento preciso en el primer juicio (haciendo valer un derecho), por más que haya podido invocar también otro fundamento, los efectos de la cosa juzgada no alcanzan al nuevo proceso. Esto porque al existir derechos o acciones concurrentes el actor hace una elección legítima que impide extender los efectos de la cosa juzgada ${ }^{86}$. Aquí el principio dispositivo hace de freno a los efectos preclusivos de la cosa juzgada.

Ahora bien, respecto del primero de los supuestos, esto es, cuando una demanda se presenta idéntica o similar en los hechos a una anterior pero difiere en su contenido jurídico la respuesta no es tan clara. Resulta difícil entender que ha operado la cosa juzgada cuando en el nuevo pleito se propone la aplicación de otro estatuto o fundamento jurídico a la relación jurídica, diferente al que se juzgó mediante la sentencia judicial. En mi opinión es insostenible justificar la procedencia de la cosa juzgada en aspectos que no han sido objeto de un debate en el proceso. Si las normas aplicables o la calificación jurídica no han podido ser discutidas en el marco de un proceso judicial, ejerciendo los litigantes en plenitud su derecho de defensa, no pueden operar los efectos de certeza y estabilidad de la cosa juzgada. En este aspecto cobra suma relevancia la distinción propuesta por cierta parte de la doctrina entre res iudicanda y res iudicata ${ }^{87}$. Esta doctrina postula, en breve síntesis, que sólo puede haber res iudicata en aquello que ha existido res iudicanda, esto es, sobre las materias que han sido propuestas y debatidas por las partes. Los efectos de estabilidad y certeza de la cosa juzgada aparecen unidos a la existencia previa de un contradictorio entre las partes, lo que otorga un criterio seguro y objetivo en la definición de la cosa juzgada.

En términos concretos, y llevada esta conclusión al ámbito de los poderes del juez en la aplicación del Derecho, si la nueva demanda se sustenta en un fundamento o calificación jurídica diferente a la anterior, adscribiendo similares, idénticos o parcialmente algunos hechos a otras normas jurídicas, no debería existir cosa juzgada, puesta ésta alcanza a lo que ha sido objeto del debate y pronunciamiento judicial. Solo hay cosa juzgada en los extremos en que las partes han situado la controversia, sin que los efectos excluyentes

${ }^{86}$ Véase: Proto, A., cit. (n. 44), p. 79.

${ }^{87}$ Nieva, J., cit. (n. 78), p. 192. Sobre la distinción: TAPIA, I., cit. (n. 82), pp. 218 yss. 
de la preclusión vayan más allá. La contradicción entre los litigantes es la frontera inexpugnable del alcance de la sentencia, lo que además de estar en armonía con los derechos de los justiciables, es un criterio lógico y seguro del alcance de la decisión. No existe cosa juzgada ni cosa juzgada virtual ahí donde el estatuto o calificación jurídica de la pretensión, además de ser diferente a lo resuelto primitivamente, no resultó materia de la discusión y resolución por el juez.

No obstante, la afirmación anterior es necesario matizarla. Si las partes discuten la calificación jurídica de los hechos expuestos en una pretensión, es decir, si hubo contradicción sobre este extremo es posible afirmar que opera la cosa juzgada en todas las calificaciones no alegadas ni resueltas por la sentencia. Hay preclusión excluyente como efecto de la cosa juzgada. La razón es más que lógica: el problema jurídico relevante fue efectivamente planteado ante un juez y las partes fueron llamadas a discutir sobre el estatuto aplicable a la controversia. Si el juez se adscribe en el fallo a una determinada tesis jurídica habrá desechado implícitamente todas las demás, aunque no hubiesen sido discutidas ni argumentadas ${ }^{88}$. Esto es evidente si se piensa que es el objeto del debate el que vincula al juez, por lo que pronunciarse sobre aspectos no debatidos implica una hipótesis de extra petita y una carga desmesurada y excesiva para el tribunal.

Sin embargo, para que la decisión que se adopte, además de ofrecer la estabilidad y certeza de la cosa juzgada, sea justa y tutele adecuadamente los derechos de los justiciables, resulta indispensable que el juez haya tenido la oportunidad en el primer juicio de someter al escrutinio de las partes todos los problemas o puntos de vista jurídicos que puedan resultar de la disputa. Se trata de extender los límites de lo debatido, dando la posibilidad de que el juez se pronuncie en base a una nueva calificación jurídica. Como también que las partes hayan gozado de la posibilidad de modificar la adscripción de los hechos a una determinada norma, cambiando el criterio de relevancia con que se ingresan al proceso. Si no se consagra esa posibilidad -como

${ }^{88}$ La cosa juzgada, de esta forma, cubre no solo lo efectivamente deducido en juicio, sino además todas las cuestiones no propuestas y que se consideran comprendidas en la esfera lógica-jurídica de la decisión, o que pueden estimarse incompatibles con la misma. Véase: LANDI, P., cit. (n. 64), p. 1226. En términos concretos, la cosa juzgada opera sus efectos sobre todas aquellas calificaciones jurídicas que resultan incompatibles con las resueltas en la sentencia definitiva, aunque no hayan sido expresamente invocadas por las partes, y sobre todos los aspectos jurídicos que son presupuestos necesarios de lo resuelto. Con todo, podría argumentarse, al igual como se hizo en el Derecho español, que los fundamentos jurídicos que no aparecían razonablemente apreciables al momento de la disputa no pueden quedar comprendidos en la decisión. Nos olvidaremos aquí si este efecto es propio de la cosa juzgada o de la preclusión. Véase, al respecto: PAdura, R., cit. (n. 3), pp. 71 y 76. 
precisamente ocurre en el actual PCPC.- nuevamente el justiciable podría verse privado de la tutela de su derecho por la imperfecta invocación de las normas jurídicas, no cumpliendo el proceso ni la jurisdicción su función primordial.

En síntesis, la única forma en que la cosa juzgada impida el desarrollo de un nuevo proceso y la dictación de un fallo sobre idéntica materia es realizando de manera adecuada un contradictorio en el primer juicio, que tenga la bondad de cubrir todos los aspectos normativos que jurídicamente puedan resultar controvertidos.

\section{CONCLUSIONES}

El campo del proceso civil ha ido generando paulatinamente una serie de reflexiones acerca de extremos que hace poco tiempo parecían inmutables; uno de ellos es la posibilidad del juez de aplicar los materiales normativos con plena libertad al caso sometido a su decisión. Se trata de una materia cuya reflexión ha partido de una constatación empírica: existen situaciones en que la pretensión del actor no encuentra sustento en los fundamentos jurídicos expuestos en la demanda pero sí en otras normas del ordenamiento jurídico que no han sido invocadas. En la necesidad de lograr una tutela efectiva de los derechos de los ciudadanos se hace necesario proponer distinciones conceptuales que permitan situar la actividad vinculante de las partes y la que puede desarrollar el juez sin limitación. De esta manera el fundamento de una demanda vincula a la jurisdicción, la que no puede modificarlo al tratarse de una actividad ligada al principio dispositivo, mientras la fundamentación constituye un espacio donde la argumentación jurídica del juzgador puede libremente utilizarse. El fundamento de la demanda se alinea con un concepto profundamente afianzado en los ordenamientos comparados -como el italiano- como es el de alegación, que en un sentido técnico-jurídico implica la adscripción que los litigantes hacen de los hechos a ciertas normas jurídicas.

Esta distinción, que tiene una naturaleza técnica-jurídica, puede justificarse en base a tres grandes argumentos. Primero, la posición actual de la jurisdicción en el contexto de la tutela de los derechos subjetivos e intereses legítimos, que impide concebir al proceso civil como un simple instrumento de resolución de disputas. En este sentido el proceso civil debe tender a proteger los derechos a quien efectivamente el ordenamiento jurídico reconoce, siendo absolutamente relevante la correcta aplicación de las normas jurídicas. Si es así entonces no resulta comprensible descargar en la parte toda la responsabilidad de invocar correctamente los fundamentos jurídicos. En segundo término la base dialéctica del proceso cobra fuerza como mecanismo para 
superar la tensión entre justifica procedimental y justicia material. El diálogo procesal, como mecanismo para legitimar la decisión, dejó de sustentarse exclusivamente en la igualdad de oportunidades, para incorporar una activa participación del juez. El contradictorio previo debe desarrollarse entre los tres sujetos que participan en el proceso: juez, demandante y demandado. Con esto existe la posibilidad de superar las denominadas "sentencias sorpresa”, pudiendo el juez, en la audiencia preliminar, plantear a las partes un cambio en la relevancia jurídica de los hechos con el afán de que sea discutida. Por último, es cierto que el juez tiene un rol relevante en la determinación del derecho aplicable, pero los abogados tienen el deber de situar la controversia en una órbita mínima de corrección jurídica.

Firme estas ideas, la atribución de amplios poderes de aplicación del Derecho tiene importantes repercusiones en ciertas instituciones relevantes del proceso civil. En la concurrencia de acciones la fijación de la acción concreta ejercida por el ciudadano impide al juez aplicar libremente las normas jurídicas, cuestión que podría solucionarse permitiendo al demandante modificar los criterios de relevancia jurídica con que introduce los hechos. Por su parte, en la concurrencia de normas, existe un consenso en orden a una pretendida libertad del juez en la aplicación del Derecho, libertad que en ocasiones puede generar verdaderas situaciones de indefensión procesal para el demandado.

Respecto de la modificación de la demanda la situación no es diferente. El proceso civil debe contener espacios para que el actor, a propuesta del juez, pueda modificar la demanda en el sentido de agregar los elementos jurídicos correctos, de manera de situar la controversia en los extremos jurídicos adecuados para obtener la tutela pretendida. Esto, por cierto, no puede lesionar la defensa del demandado, por lo que se hace necesario darle la oportunidad a éste de plantear nuevas excepciones o defensas. Con esta ecuación se logra, por un lado, morigerar los efectos de la preclusión en la actividad alegatoria, y por el otro, se impide que una demanda se destine al fracaso por la incorrecta aplicación del Derecho. Por último, en materia de cosa juzgada el límite a los efectos preclusivos se encuentra en la contradicción de los fundamentos jurídicos; no puede operar cosa juzgada en aquellos fundamentos jurídicos que no han sido objeto del debate. Pero, al contrario, tratándose de la fundamentación jurídica es razonable que la sentencia impida la renovación de un nuevo proceso que teniendo idéntico fundamento jurídico difiera en los argumentos y fundamentación jurídica. Para este efecto la cosa juzgada opera extinguiendo la posibilidad de renovar la controversia con otra fundamentación jurídica. 


\section{BiBLIOGRAFÍA}

Andolina, Italo, y Vignera, Giuseppe, I fondamento costituzionali della giustizia civile. Il modello costituzionale del processo civile italiano (Torino, Giappicchelli Editore, 1997).

BARrientos, Francisca, La responsabilidad civil del fabricante bajo el artículo 23 de la ley de protección de los derechos de los consumidores y su relación con la responsabilidad civil del vendedor, en Revista Chilena de Derecho Privado, 14 (2010).

BARros, Enrique, Tratado de responsabilidad extracontractual (Santiago, Editorial Jurídica de Chile, 2007).

Berzosa, Victoria, Demanda, “Causa Petendi” y objeto del proceso (Córdoba, Ediciones El Almendro, 1984).

Borrajo, Ignacio - DíEz-Picazo, Ignacio - Fernández, Germán, El derecho a la tutela judicial y el recurso de amparo. Una reflexión sobre la jurisprudencia constitucional (Madrid, Civitas, 1995).

Buoncristiani, Dino, L'allegazione dei fatti nel processo civile. Profili sistematici (Torino, Giappichelli, 2001).

Cabral, Antonio, Il principio del contraddittorio como diritto d' influenza e dovere di dibattito en Rivista di Diritto Processuale, 2 (2005).

Caponi, Remo - Proto, Andrea, Lineamenti di diritto processuale civile (Napoli, Jovene, 2001).

CAPONI, Remo, Brevi note sul contraddittorio in condizioni di parità nel processo civile, Civinini, Maria Giuliana - VerARDI, Carlo Maria (coordinadores), Il nuovo articolo della Costituzione e il giusto proceso civile. Atti del Convegno dell Elba (Milano, FrancoAngeli Editore, 2001).

Cappelletti, Mauro, El testimonio de la parte en el sistema de la oralidad. Contribución a la teoría de la utilización probatoria del saber privado de las partes en el proceso civil (La Plata, Librería Editorial Platense, 2002).

Cavallone, Il giudice e la prova nel processo civile (Padova, Cedam, 1991).

Chiarloni, Sergio, Questioni rilevabili d'ufficio, diritto di difesa e 'formalismo delle garanzie en Rivista Trimestrale di Diritto e Procedura Civile, 1 (1987).

Comanducci, Paolo, Alcuni problema concettuali relativi alla applicazione del diritto, en Diritto e Questioni Pubbliche, 1 (2011).

Comoglio, Luigi, Giurisdizione e proceso nel quadro delle garanzie costituzionali en Rivista Trimestrale di Diritto e Procedura Civile, 4 (1994).

Comoglio, Luigi, Imodeli di garanzia costituzionale del processo en Rivista Trimestrale di Diritto e Procedura Civile, 3 (1991).

Comoglio, Luigi, La domanda giudiziale, en Rivista Trimestrale Diritto e Procedura Civile, 62 (1988).

Corral, Hernán, Responsabilidad civil en la construcción de viviendas. Reflexiones sobre los regimenes legales aplicables a los daños provocados por el terremoto del 27 de febrero de 2010, en Revista Chilena de Derecho, 3 (2010).

CorTÉs, Valentín, Las facultades del tribunal ex art. 43,2 de la LJCA. Nota a la sentencia de la Sala cuarta del Tribunal Supremo de 17 de octubre de 1980, en Revista Justicia, 81 (1981).

De la Oliva, Andrés, Sobre la congruencia de la sentencia civil en Revista Jurídica Española La Ley, 2 (1982). 
De Santis, Francesco, Riforme processuali e "disponibilità" del regime preclusivo, en Rivista di Diritto e Procedura Civile, 4 (2004).

Delgado, Luis, Constitución, Poder Judicial y responsabilidad (Madrid, Centro de Estudios Políticos y Constitucionales, 2002).

EzQuiaga, Francisco, "Iura novit curia" y aplicación judicial del derecho (Valladolid, Lex Nova, 2008).

Ferrajoli, Luigi, "Principia iuris". Teoría del derecho y de la democracia (Madrid, Trotta, 2007).

Ferrer, Jordi, La valoración racional de la prueba (Madrid, Marcial Pons, 2007).

Ferri, Corrado, Sull effettività del contraddittorio en Rivista Trimestrale di Diritto e Procedura Civile, 42 (1989).

GARBERÍ, José, Constitución y Derecho procesal. Los fundamentos constitucionales del Derecho procesal (Madrid, Civitas, 2009).

GARNICA, Juan, El principio "iura novit curia” y la determinación del objeto del proceso en el Proyecto de reforma de la Ley de Enjuiciamiento Civil, en La Ley, 1 (1999).

Gentili, Aurelio, Contraddittorio e giusta decisione nel proceso civile en Rivista Trimestrale di Diritto e Procedura Civile, 2 (2009).

GómEz, Emilio, Concurso de leyes y concurso de acciones en el Derecho civil, en Revista de Derecho Privado, 355 (1946).

Gómez, Emilio, Derecho procesal civil.Parte general: Proceso declarativo (Madrid, Artes Gráficas y Ediciones, 1979).

Grasso, Eduardo, Note sui poteri del giudice nel nuovo proceso di cognizione in primo grado, en Rivista di Diritto Processuale, 3 (1992).

GuASCH, Sergio, El hecho y el derecho en la casación civil (Barcelona, Bosch, 1998).

Hunter, Iván, "Iura novit curia" en la jurisprudencia civil, en Revista de Derecho de la Universidad Austral de Chile, 2 (2010).

Hunter, Iván, El principio dispositivo y los poderes del juez, en Revista de Derecho de la Pontificia Universidad Católica de Valparaíso, 35 (2010).

HunTER, Iván, La aplicación judicial del derecho y la motivación de la sentencia en el PCPC., en Cuadernos de Extensión Jurídica, 23 (Santiago, U. de los Andes , 2012).

ItURRAlde, Victoria, Justificación judicial: Validez material y razones, en Analisis e Diritto, 9 (2004).

LANCEllotti, Franco, Variazioni dell'implicito rispetto alla domanda, alla pronuncia ed al giudicato, en Studi in memoria di Salvatore Satta (Milano, Cedam, 1982).

LANDI, Pasquale, Il processo civile come conoscenza logica en Rivista Trimestrale di Diritto e Procedura Civile, 62 (1988).

López, Luis, El Poder Judicial en el Estado Constitucional (Lima, Palestra Editores, 2001).

Marinoni, Luiz - Pérez Ragone, Álvaro - NúÑez, Raúl., Fundamentos del proceso civil. Hacia una teoría de la adjudicación (Santiago, Legalpublishing, 2010).

Millán, Carlos, La incongruencia civil (Madrid, Tecnos, 1983).

Monteleone, Girolamo, Diritto processuale civile (Padova, Cedam, 2002).

Morell, Luis, El juez y la Administración, frente a los hechos y el derecho aplicable, en Cosculluela Montaner, Luis (coordinador), Estudios de Derecho público económico: libro homenaje al prof. Dr. D. Sebastián Martín-Retortillo (Madrid, Civitas, 2003). 
Morón, Manuel, Derecho procesal civil (Cuestiones fundamentales) (Madrid, Marcial Pons, 1993).

Nieva, Jordi, La cosa juzgada (Barcelona, Atelier, 2006).

Nieva, Jordi, La cosa juzgada. El fin de un mito (Santiago, Legalpublishing, 2010).

NoRmand, Jacques, I poteri del giudice e delle parti quanto al fondamento delle pretensa controverse, en Rivista di Diritto Processuale, 2 (1998).

Ormazabal, Guillermo, "Iura novit curia". La vinculación del juez a la calificación jurídica de la demanda (Madrid, Marcial Pons, 2007).

Ortells, Manuel, Derecho procesal civil, ( $8^{\circ}$ edición, Navarra, Editorial Thomson Aranzadi, 2008).

Padura, Teresa, Fundamentación de la sentencia, preclusión y cosa juzgada. Su régimen en la LEC 1/2000 (Valencia, Tirant Lo Blanch, 2002).

PÉrez, Jacinto, La regla de la preclusión del artículo 400 de la Ley de Enjuiciamiento Civil, en Revista del Poder Judicial, 78 (2005).

PICARDI, Nicola, La funzione del giudice nell'interpretazione e nell'applicazione del diritto, en Giustizia Civile, 53 (2003).

PiCardi, Nicola, Manuale del processo civile (Milano, Giuffrè Editore, 2006).

Picó i Junoy, Joan, La modificación de la demanda en el proceso civil (Valencia, Tirant lo Blanch, 2006).

Pivetti, Marco, Per un processo civile giusto e ragionavole, en Civinini, Maria Giuliana - Maria Verardi, Carlo (coordinadores), Il nuovo articolo della Costituzione e il giusto proceso civile. Atti del Convegno dell' Elba (Milano, FrancoAngeli Editore, 2001).

PRIETO, Leonardo, El cambio del punto de vista jurídico, en Revista de Derecho Procesal, 1 (1956).

Proto, Andrea, Lezioni di Diritto processuale civile (Napoli, Jovene Editore, 1999).

Ricci, Gian, L'allegazione dei fatti nel nuovo processo civile, en Rivista Trimestrale di Diritto e Procedura Civile, 3 (1992).

Romero, Alejandro, Curso de Derecho procesal civil (Santiago, Editorial Jurídica de Chile, 2012), I.

Romero, Alejandro, La cosa juzgada en el proceso civil chileno. Doctrina y jurisprudencia (Santiago, Editorial Jurídica de Chile, 2002).

Sentís, Santiago, El juez y el Derecho (Buenos Aires, Ediciones Jurídicas EuropaAmérica, 1957).

Serrano, Gregorio, La probibición de indefensión y su incidencia en el proceso (Granada, Editorial, 1997).

Silguero, Joaquín, La preclusión de alegaciones en el proceso civil (Pamplona, Thomson Reuters, 2009).

Sommaggio, Paolo, La centralità del contraddittorio nell'esperienza giuridica. Prima riflesioni per una teoria radicale, en Diritto \& Questioni Pubbliche, 7 (2007).

TAPIA, Isabel con Cavanillas Múgica, La concurrencia de responsabilidad contractualy extracontractual. Tratamiento sustantivo y procesal (Madrid, Editorial Centro del Estudios Ramón Areces, 1995).

TAPIA, Isabel, El objeto del proceso. Alegaciones. Sentencia. Cosa juzgada (Madrid, Editorial La Ley, 2000).

TAPIA, Isabel, La cosa juzgada (Estudio de jurisprudencia civil) (Madrid, Dykinson, 2010). 
TARuffo, Michele, Le preclusioni nella reforma del proceso civile, en Rivista di Diritto Processuale, 1 (1992).

Taruffo, Michele, Páginas sobre la justicia civil (Madrid, Marcial Pons, 2009).

Tarzia, Giuseppe, Poteri delle parti e poteri del giudice en Problemi del proceso civile di cognizione (Padova, Cedam, 1989).

TOHARÍA, José, ¿Qué esperan los ciudadanos de la justicia?, en Poder judicial y servicio público (Madrid, Consejo General del Poder Judicial, 2006).

Trocker, Nicolò, Processo civile e costituzione. Problemi di diritto tedesco e italiano (Milano, Giuffrè, 1974).

Verde, Giovanni, Profili del proceso civile. Parte generale (Napoli, Jovene, 1988).

YllesCA, Rafael, El principio "iura novit curia" y la posición del abogado en el proceso, en La Ley, 3 (1994). 